\title{
Catalytic dearomative hydroboration of heteroaromatic compounds
}

\author{
BASUJIT CHATTERJEE ${ }^{\mathrm{a}, \mathrm{b}}$ and CHIDAMBARAM GUNANATHAN ${ }^{\mathrm{b}, *}$ (D \\ a Present address: Max Planck Institute for Chemical Energy Conversion, Stiftstraße 34-36, \\ 45470 Mülheim an der Ruhr, Germany \\ ${ }^{\mathrm{b}}$ School of Chemical Sciences, National Institute of Science Education and Research, HBNI, \\ Bhubaneswar 752 050, Odisha, India \\ E-mail: gunanathan@niser.ac.in
}

MS received 26 June 2019; revised 31 October 2019; accepted 31 October 2019; published online 3 December 2019

\begin{abstract}
This review offers a comprehensive discussion on literature concerning the development of catalytic protocols for the dearomative hydroboration of heteroaromatic compounds. The importance of selective dearomatization of heteroarenes, their remarkable applications along with the development of different catalytic methods and their synthetic scopes are emphasized.
\end{abstract}

Keywords. Dihydropyridines; heterocycles; hydroboration; catalysis; dearomatization.

\section{Introduction}

Dihydropyridine (DHP) derivatives are ubiquitous and play an important role in biologically active species, such as dearomatization/aromatization of pyridine motif in $\mathrm{NAD}^{+} / \mathrm{NADH}$ redox couple (Scheme 1a). ${ }^{1}$ Such reactivity is also central to the pharmaceutically important molecules such as Hantzsch ester. ${ }^{1,2}$ More than $92 \%$ of drug molecules contain nitrogen-containing heterocycles and DHPs play a significant role among them. 1,4-Dihydropyridines are found to have widespread applications such as $\mathrm{Ca}^{2+}$ channel blocker, and in treatment of cardiovascular and Alzheimer's diseases, dementia, diabetic neuropathy and multidrug resistance (MDR). ${ }^{3}$ They are also useful synthetic intermediates while developing complex natural products and pharmaceuticals such as the asymmetric synthesis of influenza drug (-)- oseltamivir (Tamiflu, Scheme 1b). ${ }^{4}$ Drug molecules such as amlodipine, nimodipine, and nifedipine containing DHP motif are widely used to cure various ailments (Scheme 1c). ${ }^{5}$

As dearomatized heteroaromatic compounds have much importance in numerous fields, various synthetic approaches have been developed. ${ }^{6}$ However, the protocols suffer from the employment of harsh reaction conditions and stoichiometric activating reagents, hence they are not selective and often lead to competing over-reductions. ${ }^{7}$ Fowler's method for selective reduction of pyridines involve the initial formation of

*For correspondence pyridinium salt and thus require stoichiometric activating reagents. ${ }^{8}$ Direct catalytic hydrogenation of heteroarenes leads to over-reduction and results in the formation of saturated heterocycles. ${ }^{7}$ Therefore, the challenge remains in developing a mild catalytic protocol to provide a selective reduction of heteroarenes. In this direction catalytic hydrosilylation, ${ }^{9}$ silaboration, ${ }^{10}$ phosphinoboration ${ }^{11}$ and hydroboration reactions provide the scope and synthetic methods to perform a selective reduction of heteroarenes. This review will focus on the recent developments of catalytic hydroboration of heteroarenes (Scheme 2). As this review article is for the special issue on periodic table and for convenience of the readers, it is organized in segments with respect to s-, p-, d- and f-block elements as catalysts starting from the inner-transition metals (f-block) to finally alkali and alkaline earth metals (s-block).

\section{Hydroboration of heteroarenes catalyzed by f- block elements}

Eisen and coworkers have reported a Th-catalyzed hydroboration of substituted pyridines. $^{12}$ After screening different Th-catalysts, complex $\mathbf{1}$ was found to have efficient reactivity towards selective 1,2-hydroboration of pyridines at $70{ }^{\circ} \mathrm{C}$. Lowering of temperature leads to the decrease of product yields, therefore under the optimized reaction condition $\left(70{ }^{\circ} \mathrm{C}, 24 \mathrm{~h}, 2 \mathrm{~mol} \%\right.$ of $\left.\mathbf{1}\right)$, an assortment of 
(a)<smiles>NC(=O)c1ccc[n+]([Pb](=O)[O-])c1</smiles>

NAD ${ }^{+}$

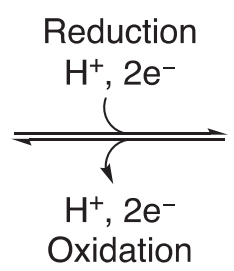

Oxidation<smiles>NC(=O)C1=CN([R8](=O)[O-])C=CC1</smiles>

NADH

(b)<smiles>[R]OC(=O)C1=C[C@H](OC(CC)CC)C(NC2CCCCC2)[C@H](N)C1</smiles>

(-)-Oseltamivir (Tamiflu)

(c)<smiles>CCOC(=O)C1=C(C)NC(C)=C(C(=O)OCC)C1c1ccccc1[N+](=O)[O-]</smiles>

Nifedipine (Adalat ${ }^{\circledR}$-Bayer)<smiles>CCOC(=O)C1=C(C)NC(COCCN)=C(C(=O)OCC)C1c1ccccc1Cl</smiles><smiles>COCCOC(=O)C1=C(C)NC(C)=C(C(=O)O)C1c1ccccc1[N+](=O)[O-]</smiles>

Nimodipine (Nimotop®-Bayer)

Scheme 1. Applications of dihydropyridines and their role in nature.

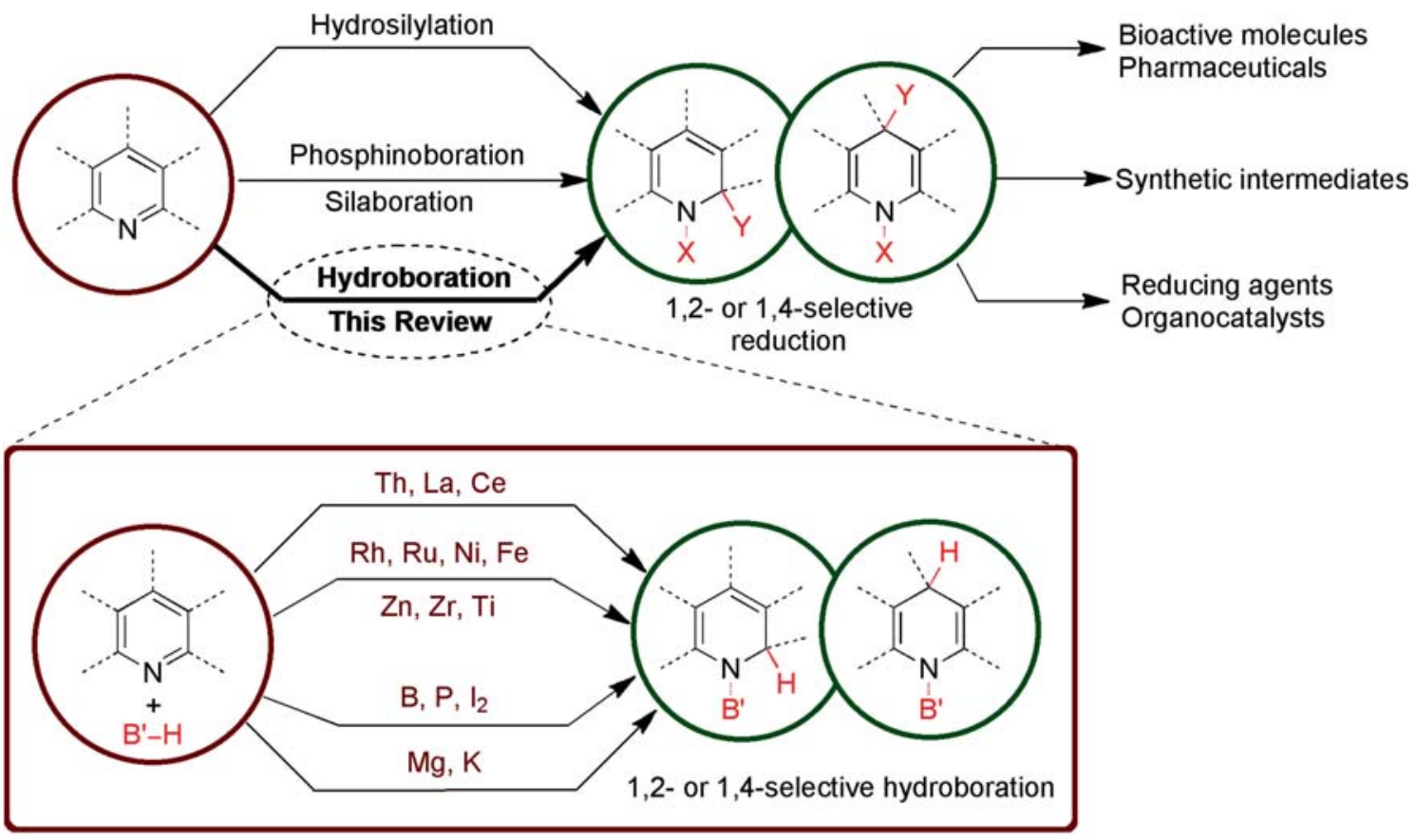

Scheme 2. Catalytic methods for selective reduction of pyridines and scope of this review.

substituted pyridines underwent selective 1,2-hydroboration (Scheme 3). Different pyridine compounds containing methoxy, fluoro and methyl functionalities at 3-position provided good to excellent yields. However, strong electron donation at 4-position leads to the gradual decrease of yields $\left(\mathrm{Et}>\mathrm{OMe}>\mathrm{NMe}_{2}\right)$.
Also, substituents at 2-position of pyridine failed to provide the corresponding products perhaps due to steric encumbrance.

Marks and co-workers have described an effective organolanthanide complex 2 catalyzed regioselective 1,2-hydroboration of pyridines comprising of a broad 


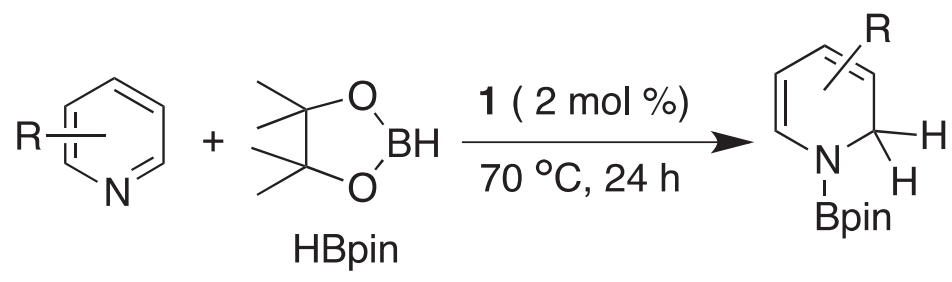<smiles>[R8]N1C=CC=C(F)C1</smiles>

$88 \%$<smiles>CCC1=CCC(Br)N(Br)C=C1</smiles>

$73 \%$<smiles>CC1=CC=CN(Br)C1</smiles>

$95 \%$<smiles>COC1=CCC(Br)N(Br)C=C1</smiles>

$60 \%$<smiles>COC1=CC=CN(Br)C1</smiles>

$67 \%$<smiles>CN(C)C1=CC(Cc2ccccc2)N(c2ccccc2)C=C1</smiles>

$0 \%$

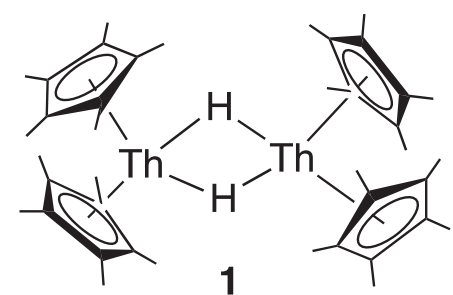

1<smiles>Pc1ccccc1</smiles>

$99 \%$<smiles>[R]C1=CC=CCN1B</smiles>

$0 \%(\mathrm{R}=\mathrm{Cl}, \mathrm{Br}, \mathrm{Me})$

Scheme 3. Thorium-catalyzed regioselective 1,2-hydroboration of pyridines.

substrate scope under mild reaction condition (Scheme 4). ${ }^{13}$ The protocol has good functional group tolerance ranging from electron-donating to withdrawing functionality. Both steric and electronic factors played crucial roles in determining the reactivity of the catalyst. Where 2-substituted pyridines failed to provide the corresponding products, substrates having a variety of functional groups such as $\mathrm{CF}_{3}, \mathrm{OMe}, \mathrm{SnMe}_{3}$, and halogens were well tolerated under the optimized reaction condition. Mechanistic studies of this protocol reveal that $\mathrm{C}=\mathrm{N}$ bond insertion into the $\mathrm{La}-\mathrm{H}$ bond as turnover determining step. Detailed kinetic measurements revealed first-order rate law with respect to catalyst, fractional-order in pyridine, and inverse first order with pinacolborane concentrations.

A metal-organic framework (MOF) catalyst 3 containing cerium $(\mathrm{CeH}-\mathrm{BTC}, \mathrm{BTC}=$ benzene-1,3,5-tricarboxylic acid) was developed by Lin and coworkers, for catalytic hydroboration and hydrophosphination reactions (Scheme 5). ${ }^{14}$ When reacted with pyridine and HBpin, the CeH-BTC catalyst provided $71 \%$ of 1,4-regioselective product at $80{ }^{\circ} \mathrm{C}$ in $36 \mathrm{~h}$ with minor amount of 1,2-regioselective product. The protocol also tolerates 1,4-regioselective hydroboration of 3-bromo, 3-methyl, and 3,5-dimethyl pyridines. Under similar reaction condition quinolines also undergo regioselective hydroboration in good yields.

\section{Hydroboration of heteroarenes catalyzed by d- block elements}

When subjected to the $\mathrm{Rh} / \mathrm{PCy}_{3}\left(\mathrm{Rh}=[\mathrm{Rh}(\mathrm{COD}) \mathrm{Cl}]_{2}\right.$ 4) catalytic system, substituted pyridines underwent efficient 1,2-regioselective hydroboration. ${ }^{15}$ Various functional groups including trifluoromethyl, esters, methoxy were amenable under the optimized reaction condition (Scheme 6). The possible mechanism is proposed based on the general mechanistic pathway of alkynes and alkene hydroboration, which involves oxidative addition of $\mathrm{B}-\mathrm{H}$ bond to $\mathrm{Rh}(\mathrm{I})$ center and concomitant coordination of pyridine. The following insertion of pyridine into the $\mathrm{Rh}-\mathrm{H}$ bond and finally, reductive elimination leads to the formation of the desired product.

Recently, we have developed an efficient method for ruthenium-catalyzed regioselective 1,4-dearomatization of pyridine derivatives using pinacolborane. ${ }^{16}$ 


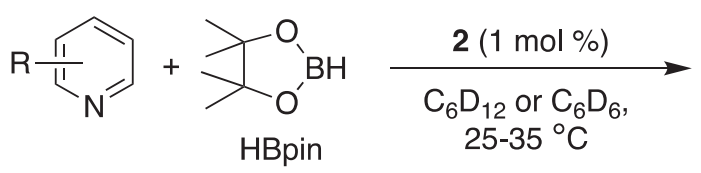

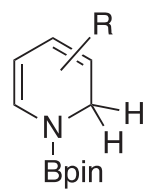

1,4-<smiles>Pc1ccccc1</smiles>

$99 \%, 3 \mathrm{~h}$<smiles>COC1=CCN(c2ccccc2)C=C1</smiles>

$97 \%, 7.5 \mathrm{~h}$<smiles>CSC1=CCN(c2ccccc2)C=C1</smiles>

$97 \%, 2 \mathrm{~h}$<smiles>O=C(O)N1C=CC(N2CCCCC2)=CC1</smiles><smiles>FC1=CC=CN(Bc2ccccc2)C1</smiles><smiles>ClC1=CC=CN([R8]c2ccccc2)C1</smiles>

$99 \%, 0.8 \mathrm{~h}$<smiles>BN1C=C(C)C=C(C)C1C</smiles>

$97 \%, 3.3 \mathrm{~h}$<smiles>CC1=CN(c2ccccc2)C(C2CCCN2C)C=C1</smiles>

$98 \%, 1 \mathrm{~h}$<smiles>Brc1ccccc1</smiles>

$92 \%, 15 \mathrm{~h}$ 2 equiv HBpin

Scheme 4. Lanthanum-catalyzed regioselective 1,2-hydroboration of $N$-heteroarenes.

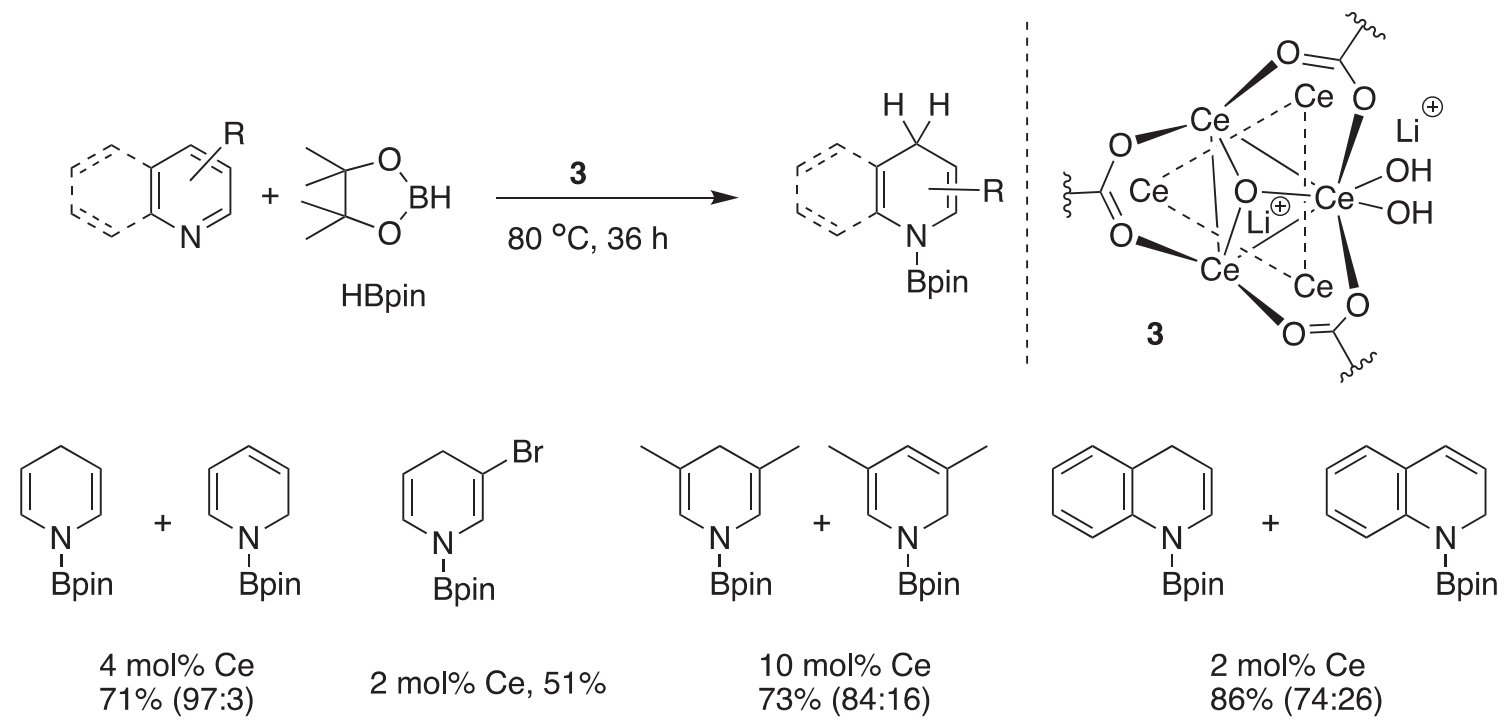

Scheme 5. Cerium-catalyzed regioselective 1,4-hydroboration of $N$-heteroarenes.

Catalytic intermediates involved in this process are isolated, characterized and further used as effective catalysts. Also in situ NMR studies and a detailed mechanistic investigation revealed the active presence of two intermediates [Ru(p-cymene $) \mathrm{Cl}_{2}(\mathrm{Py})\left(\mathrm{P}(\mathrm{Cy})_{3}\right)$ ] 7 and $\left[\mathrm{Ru}(\mathrm{p}\right.$-cymene $\left.)(\mathrm{H}) \mathrm{Cl}(\mathrm{Py})\left(\mathrm{PCy}_{3}\right)\right] \mathbf{8}$ in solution 


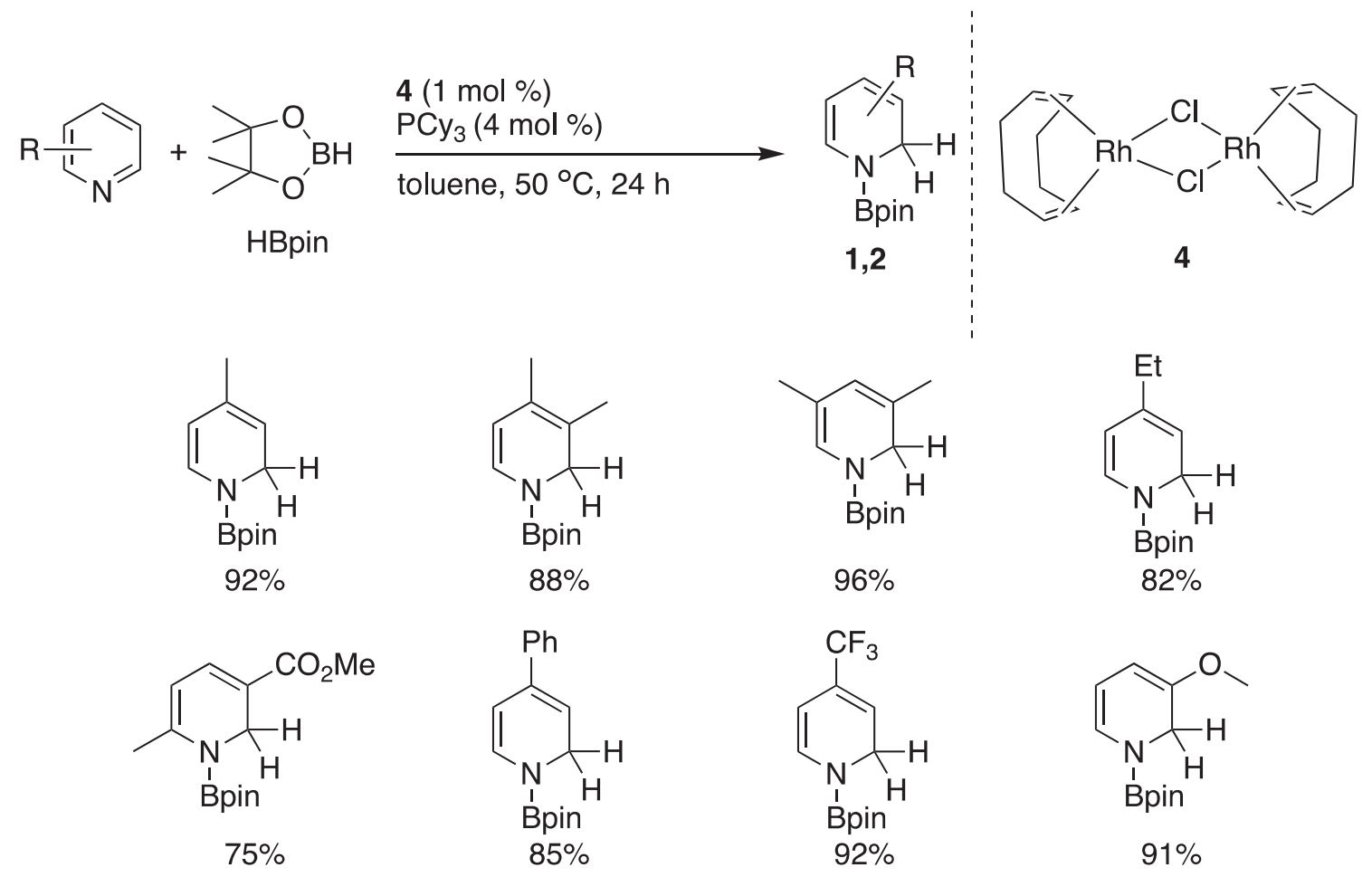

Scheme 6. Rhodium-catalyzed regioselective 1,2-hydroboration of pyridines.

during the progress of the reaction. Complex 5 was found to be an active catalytic intermediate. After optimization of the reaction condition, employing complex $5\left[\mathrm{Ru}(\mathrm{p}\right.$-cymene $\left.) \mathrm{Cl}_{2}\left(\mathrm{PCy}_{3}\right)\right]$ as a catalyst, regioselective 1,4-hydroboration was explored for the substituted pyridines. A wide range of 3-substituted pyridines is amenable to the reaction, which provided exclusive 1,4-regioselectivity on resulted hydroboration products. Alkyl, aryl, heteroaryl, ester, amine, amide, alkoxy, and acyloxy functional groups are well-tolerated in this catalytic protocol. Remarkably, with 3-(pyridin-3-ylmethoxy)pyridine catalytic bis1,4-hydroboration occurred successfully. However, 2-substituted pyridines (vide infra) do not undergo hydroboration reaction due to steric hindrance (Scheme 7).

A series of fundamental stoichiometric and catalytic investigations along with in situ NMR studies allowed us to rationalize and propose the following mechanism for the 1,4-regioselective hydroboration of pyridine (Scheme 8). The reaction of 5 with $\mathrm{PCy}_{3}$ or reaction of 6 with pyridine leads to the formation of common intermediate 7, which after reaction with HBpin generates $\mathrm{Ru}-\mathrm{H}$ intermediate 8. Remarkably, 1,3-hydride transfer prevails in $\mathbf{8}$, over 1,5-hydride transfer; perhaps, due to the steric hindrance between the " $\mathrm{sp}^{3}$ $\mathrm{CH}_{2}$ " of the amide ligand at the 2-position of pyridine ligand and $\mathrm{PCy}_{3}$ motif in Ia, which could appear upon 1,2-addition on the pyridine. The electronic factors might play a key role in preventing the commonly observed 1,3-hydride transfer. ${ }^{17}$ Therefore, subsequent intramolecular "1,5-hydride transfer" leads to the regioselective 1,4-hydroboration of pyridine and generates amide ligated $\mathrm{Ru}(\mathrm{II})$ intermediate $\mathbf{I}$. Further, the reaction of HBpin with I provides intermediate II and followed by transmetalation of amide ligand affords the desired regioselective 1,4-hydroboration of pyridine and transient intermediate III. Coordination of pyridine to III regenerates the intermediate $\mathbf{8}$, which persists in the reaction mixture throughout the catalytic process.

Added phosphine ligand could improve the reactivity of the catalyst. This is evident from the reaction of $\mathrm{Ni}(\mathrm{acac})_{2} \mathbf{9}$. When used alone, catalyst 9 has little effect on heteroarene hydroboration. However, the addition of phosphine ligand afforded enhanced product formation and 1,4-regioselectivity (Scheme 9). ${ }^{18}$ After substantiating different phosphine ligands, the protocol has been optimized with tricyclopentylphosphine $\left(\mathrm{PCyp}_{3}\right)$ as a suitable ligand with $\mathrm{Ni}(\mathrm{acac})_{2}$ as a catalyst. A series of heteroarenes, including quinoline, benzoquinoline, isoquinoline, acridine and phenanthroline displayed efficient reactivity towards regioselective 1,4-hydroboration. Pyridines containing 
<smiles>Cc1ccc(C(C)C)cc1[Te](Cl)(Cl)Br</smiles><smiles>O=C(O)N1C=CCC=C1</smiles><smiles>BN1C=CCC(C)=C1</smiles>
$97 \%(93 \%), 7 \mathrm{~h}$<smiles>CC1C=CN(Br)C=C1</smiles>
$0 \%, 7 \mathrm{~h}$<smiles>O=C1CCCCCN1CC1=CN(Br)C=CC1</smiles>
$>99 \%(93 \%), 3.5 \mathrm{~h}$<smiles>[B]N1C=CCC(COC2=CN(B)C=CC2)C=C1</smiles>

$48 \%, 3.5 \mathrm{~h}$
$96 \%(91 \%), 7 \mathrm{~h}$<smiles>Brc1cccc(CN2CCCC2)c1</smiles>

$94 \%, 7 \mathrm{~h}$<smiles>CCOC(=O)CC1=CN(Br)C=CC1</smiles>

$>99 \%(92 \%), 14 \mathrm{~h}$<smiles>CC(=O)OC1=CN([B]c2ccccc2)C=CC1</smiles>

$85 \%, 14 \mathrm{~h}$<smiles>CCC1=CN(B(Br)c2ccccc2)C=CC1</smiles>

$92 \%(86 \%), 7 \mathrm{~h}$<smiles>Brc1cccc(Cn2cccc2)c1</smiles>

$>99 \%(94 \%), 7 \mathrm{~h}$<smiles>COC1=CN(Br)C=CC1</smiles>

$59 \%, 7 \mathrm{~h}$<smiles>O=C(OC1=CN([B]c2ccccc2)C=CC1)c1ccccc1</smiles>

$37 \%, 4 \mathrm{~h}$<smiles>CC1=CN(B(Br)c2ccccc2)C=C(C)C1</smiles>

$61 \%(57 \%), 7 \mathrm{~h}$<smiles>Brc1cccc(Cn2ccc3ccccc32)c1</smiles>

$>99 \%(91 \%), 7 \mathrm{~h}$<smiles>[R8](c1ccccc1)N1C=CCC(OCc2ccccc2)=C1</smiles>

$82 \%(77 \%), 7 \mathrm{~h}$

Scheme 7. Ruthenium-catalyzed regioselective 1,4-hydroboration of pyridines.

various functionalities such as alkyl, aryl, esters, and methoxy are also endured under the optimized reaction condition.

The activation of $\mathrm{E}-\mathrm{H}(\mathrm{E}=\mathrm{Si}, \mathrm{B})$ bonds can occur in a cooperative metal-ligand reactivity to provide
$\mathrm{M}-\mathrm{H}$ bond and silylium and borenium ions for catalytic hydrosilylation or hydroboration reactions. ${ }^{19}$ Ruthenium-thiolate system has been developed for the activation of hydrosilanes, giving a $\mathrm{Ru}(\mathrm{II})-\mathrm{H}$ species with the sulfur-stabilized silicon cation for 1,4- 


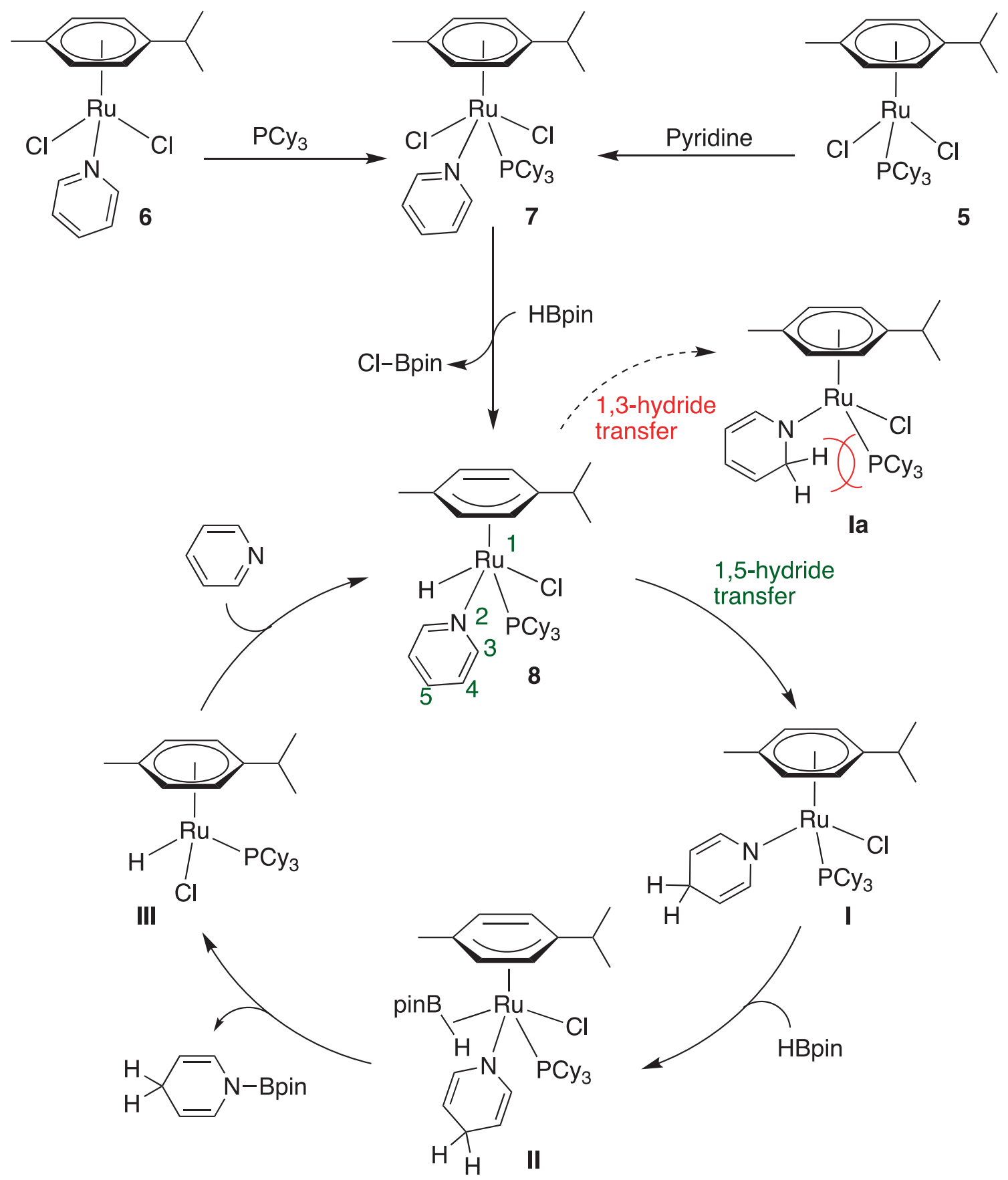

Scheme 8. Proposed mechanism for the ruthenium-catalyzed hydroboration of pyridine.

hydrosilylation of pyridines. ${ }^{20}$ The challenge remains in tuning the reactivity of Lewis acid-base coordination sphere interaction for the activation of $\mathrm{E}-\mathrm{H}(\mathrm{E}=$ $\mathrm{Si}, \mathrm{B})$ bonds. Later a well-defined nickel(II)-cooperative catalyst having phosphine-phenolato ligand backbone provided similar reactivity in activation of hydroboranes (Scheme 10). ${ }^{21}$

Further substrate scope was investigated for the hydroboration of pyridines with the optimized condition in the presence of the catalyst $\mathbf{1 2}$. Various functional groups such as $-\mathrm{CF}_{3},-\mathrm{Bpin},-\mathrm{OMe}$ remain unaffected under the optimized catalytic condition and provided the corresponding regioselective 1,2-hydroboration products in good to excellent yields. However, the steric hindrance at 2-position of pyridine prevents reaction and also the protocol is failed on substrates containing halogen substituents, which resulted in the formation of unidentified products (Scheme 11).

An $\mathrm{N}_{2}$-bridged diiron complex was developed by Wang and coworkers, as an efficient precatalyst for the 
<smiles></smiles><smiles>Brc1ccccc1</smiles><smiles>CC1C=CN(Br)C=C1</smiles><smiles>CN1C=CC(c2ccccc2)C=C1</smiles>

Bpin<smiles>CCC1C=CN(Br)C=C1</smiles><smiles>CN1C=CC(C(F)(F)F)C=C1</smiles>

$67 \%$

$63 \%$

$71 \%$

$85 \%$

$94 \%$<smiles>[C+]1C=CN(Cc2ccccc2)N(Cc2ccccc2)c2ccccc21</smiles>

$89 \%(70: 30)$<smiles>C1=CN(c2ccccc2)c2ccc3ccccc3c2C1</smiles>

$96 \%$<smiles>CC(C)(C)c1ccccc1</smiles>

$57 \%$

Scheme 9. Nickel-catalyzed regioselective 1,4-hydroboration of $N$-heteroarenes.
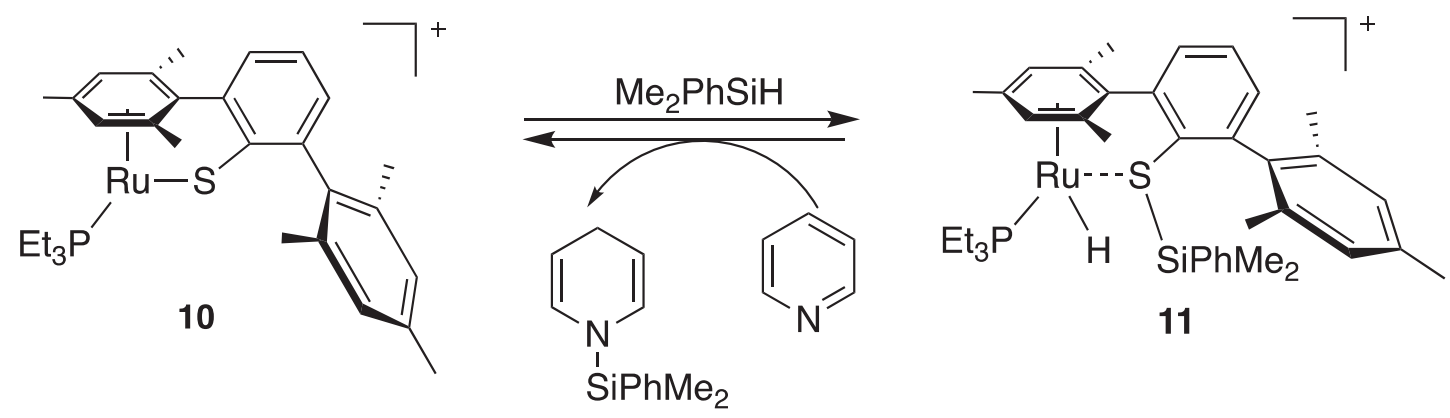

11

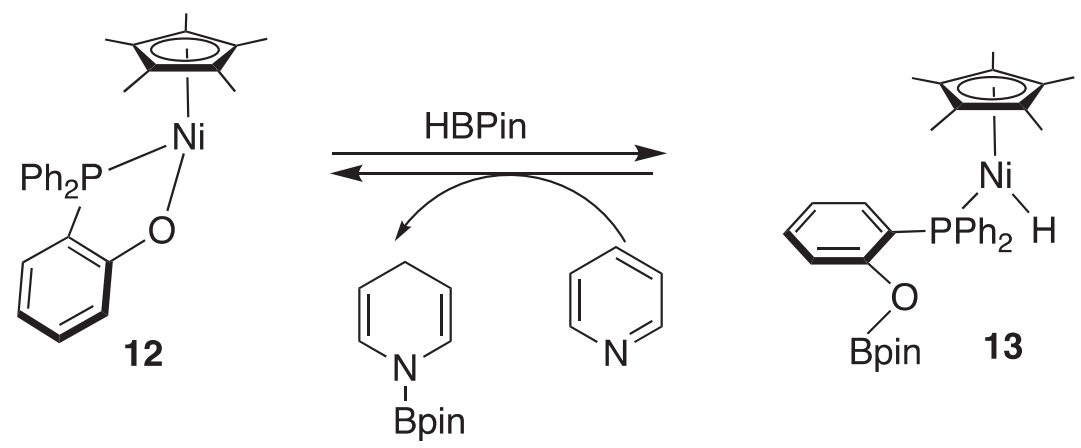

Scheme 10. Metal-ligand cooperative effect in silane and borane activation. 
regioselective 1,2-hydroboration of $\mathrm{N}$-heteroarenes with HBpin. ${ }^{22}$ A series of substrates were subjected to the hydroboration reaction under the optimized reaction condition. Pyridines having both electron-donating and electron-withdrawing functionality underwent efficient hydroboration to provide the corresponding 1,2-dearomatized products. Functional groups such as $\mathrm{CF}_{3}$, phenyl, $\mathrm{OMe}$, and $\mathrm{COOMe}$ were well tolerated under the reaction conditions. Electron-withdrawing groups on pyridine accelerate the hydroboration. Also, challenging reduction of isoquinolines, phenanthridines and substituted benzimidazoles proceeded smoothly at room temperature to afford the corresponding 1,2-hydroboration products in good to excellent yields (Scheme 12).

On the basis of kinetic and experimental evidence, Wang and coworkers have proposed the catalytic cycle. In the case of ruthenium(II)-thiolate system generation of borenium ions from pinacolborane has been described. ${ }^{23}$ For iron-thiolate system facile hydride transfer from HBpin to IV via sulfur-boron interaction in intermediate $\mathbf{V}$ and upon the $\mathrm{B}-\mathrm{H}$ bond cleavage (VI), subsequent transfer of the borenium ion to the reduced $N$-heterocycle leads to the formation of the final product and regenerates the 16-electron iro$\mathrm{n}$ (II) active species VII. The regioselectivity of the dihydropyridine products is determined by the substituent on the substrates (Scheme 13).

Nikonov and coworkers have described an efficient zinc hydride $\mathrm{NacNacZnH} 15$ (NacNac = $\left.[\mathrm{ArNC}(\mathrm{Me}) \mathrm{CHC}(\mathrm{Me}) \mathrm{NAr}]^{-}, \mathrm{Ar}=2,6-\mathrm{Me}_{2} \mathrm{C}_{6} \mathrm{H}_{3}\right)$ for 1,2-regioselective hydroboration of $\mathrm{N}$-heterocycles (Scheme 14). ${ }^{24}$ While the catalyst has lower efficiency towards hydrosilylation of $N$-heterocycles, more Lewis acidic borane reacted efficiently and provided regioselective 1,2-hydroboration with better yields. When subjected to the optimized reaction condition, quinoline underwent selective hydroboration in $96 \%$ yield at room temperature in $1.2 \mathrm{~h}$. The yield for reduction of sterically hindered quinoline was low, but

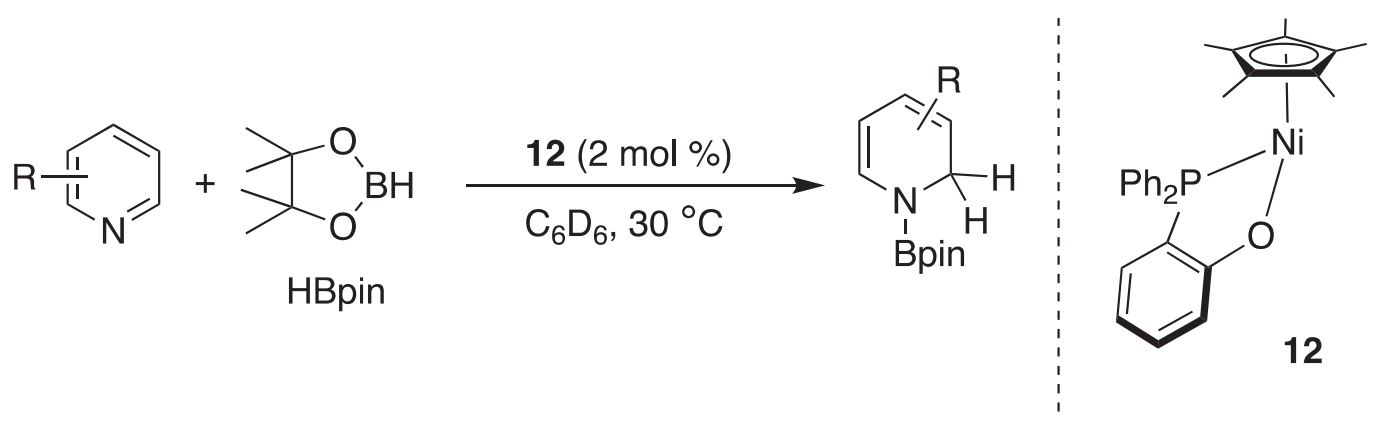<smiles>CC1=CC(Cc2ccccc2)N(Cc2ccccc2)C=C1</smiles>

$99 \%, 12 \mathrm{~h}$<smiles>CCC1=CCN(c2ccccc2)C=C1</smiles>

$91 \%, 12 \mathrm{~h}$<smiles>Pc1ccccc1</smiles>

$75 \%, 18 h$<smiles>FC(F)(F)C1=CCCN(Bc2ccccc2)C=C1</smiles>

$69 \%, 24 h$<smiles>O=C(O)C1=CC(Cc2ccccc2)N(Cc2ccccc2)C=C1</smiles>

$69 \%, 24 h$<smiles>COC1=CC=CN(Cc2ccccc2)C1</smiles>

$80 \%, 12 \mathrm{~h}$<smiles>[CH+][C@H]1C=CC(C)=CN1Cc1ccccc1</smiles>

$94 \%, 24 \mathrm{~h}$ $1,2-: 1,4-: 1,6-=49: 29: 22$<smiles>Cc1ccccn1</smiles><smiles>Clc1cccnc1</smiles>

Scheme 11. Nickel-catalyzed regioselective 1,2-hydroboration of pyridines. 
<smiles>C1=CCC2CCC(C2)N=c2ccccc2=C1</smiles>

$61 \%, r t, 24$ h<smiles>CC1(C)OBOC1(C)C</smiles><smiles>FC(F)(F)C1=CCCN(Cc2ccccc2)C=C1</smiles>

$99 \%, r t, 24 \mathrm{~h}$
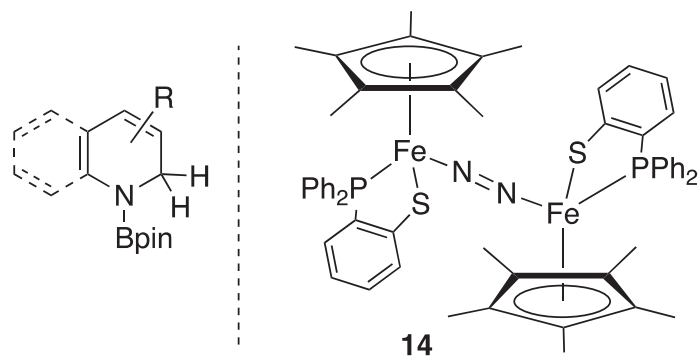

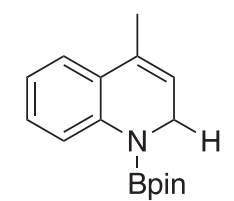

$94 \%, 50{ }^{\circ} \mathrm{C}, 40 \mathrm{~h}$

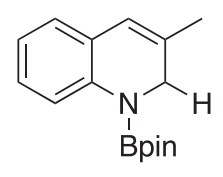

$89 \%, r t, 40 \mathrm{~h}$<smiles>C1=CN(Cc2ccccc2)CC=C1c1ccccc1</smiles>

$95 \%, 50^{\circ} \mathrm{C}, 24 \mathrm{~h}$<smiles>COC1=CC=CN([R8]c2ccccc2)C1</smiles>

$83 \%, 50^{\circ} \mathrm{C}, 24 \mathrm{~h}$<smiles>c1ccc(-c2ccccn2)cc1</smiles>

$50{ }^{\circ} \mathrm{C}, 24 \mathrm{~h}$ No reaction<smiles>CC1=CC(C)N(Cc2ccccc2)C(C)=C1</smiles>

$79 \%, 50{ }^{\circ} \mathrm{C}, 36 \mathrm{~h}$

Scheme 12. Catalytic regioselective 1,2-hydroboration by iron complex 14.

acridine provided a better yield $(90 \%)$ in comparison with hydrosilylation. Pyrazine, pyrimidine, and even pyridine underwent efficient hydroboration with excellent yields.

Lin and coworkers have developed a quantitative conversion of $\left[\mathrm{M}_{6}^{\mathrm{IV}}\left(\mu_{3}-\mathrm{O}\right)_{4}\left(\mu_{3}-\mathrm{OH}\right)_{4} \mathrm{Cl}_{12}\right]^{6-}$ nodes into $\mathrm{MCl}_{2}$-BTC metal-organic framework (MOF), which upon reaction with $\mathrm{NaEt}_{3} \mathrm{BH}$ leads to the formation of $\mathrm{M}^{\mathrm{III}} \mathrm{H}-\mathrm{BTC}(\mathrm{M}=\mathrm{Zr}$, Hf; BTC is 1,3,5-benzenetricarboxylate) via bimetallic reductive elimination of $\mathrm{H}_{2}$ (Scheme 15). ${ }^{25}$ The unique property of coordinative unsaturation of $\mathrm{Zr}^{\mathrm{III}} \mathrm{H}-\mathrm{BTC}$ (16) makes it a highly active catalyst for 1,4-selective hydroboration of pyridines and quinolines. Upon heating a mixture of pyridine and HBpin for $18 \mathrm{~h}$ in presence of $0.2 \mathrm{~mol} \%$ of 16 at $90{ }^{\circ} \mathrm{C}$ provided regioselective 1,4-addition product in good $(73 \%)$ yield [TON of 365]. A wide range of pyridine derivatives, such as 3-methylpyridine, 3,5-dimethylpyridine, and pyridines containing reducible functionalities like bromo, nitrile, ester, and amide groups underwent efficient reaction with high TONs and 1,4- regioselectivity. Moreover, quinoline, 6-methoxyquinoline, and 6-methylquinoline, have provided efficient regioselective 1,4-hydroboration. Substrates, such as isoquinoline resulted in 1,2-hydroboration with high activity, as it lacks the opportunity to undergo 1,4-hydroboration. $\mathrm{Hf}^{\mathrm{III}} \mathrm{H}$-BTC was also active for 1,4-hydroboration of pyridine; however less efficient than $\mathrm{Zr}$, which delivered $57 \%$ of product formation under similar reaction condition.

Later, Lin and coworkers have developed a novel $\mathrm{Ti}_{3}$-BPDC metal-organic framework (MOF) having biphenyl-4,4'-dicarboxylate (BPDC) linkers and $\mathrm{Ti}_{3}(-$ $\mathrm{OH})_{2}$ as secondary building units (SBUs) with permanent porosity (Scheme 16). ${ }^{26}$ The unique structure of $\mathrm{Ti}-\mathrm{BPDC}$ in vicinity of the adjacent $\mathrm{Ti}^{\mathrm{IV}}-\mathrm{OH}$ groups helped the SBUs to support $\mathrm{Co}^{\mathrm{II}}$-hydride species for efficient cascade reduction via consecutive dearomative hydroboration and hydrogenation of $\mathrm{N}$ heteroarenes. When employed to the optimized condition a series of pyridines containing different functional groups, such as alkoxy, ester, dialkyl amide, and silyl groups, underwent efficient cascade hydroboration and hydrogenation to provide piperidines. The method has the optimum result when n-octane was used as a solvent. Changing n-octane to coordinating solvents or neat condition leads to a detrimental effect on the yields suggesting inhibition from coordination in the active site. Pyridines with electron-donating or withdrawing groups on 3-, 4-, or 5- positions of the pyridine rings were efficiently reduced to piperidines in good to excellent yields (73-100\%). Also 


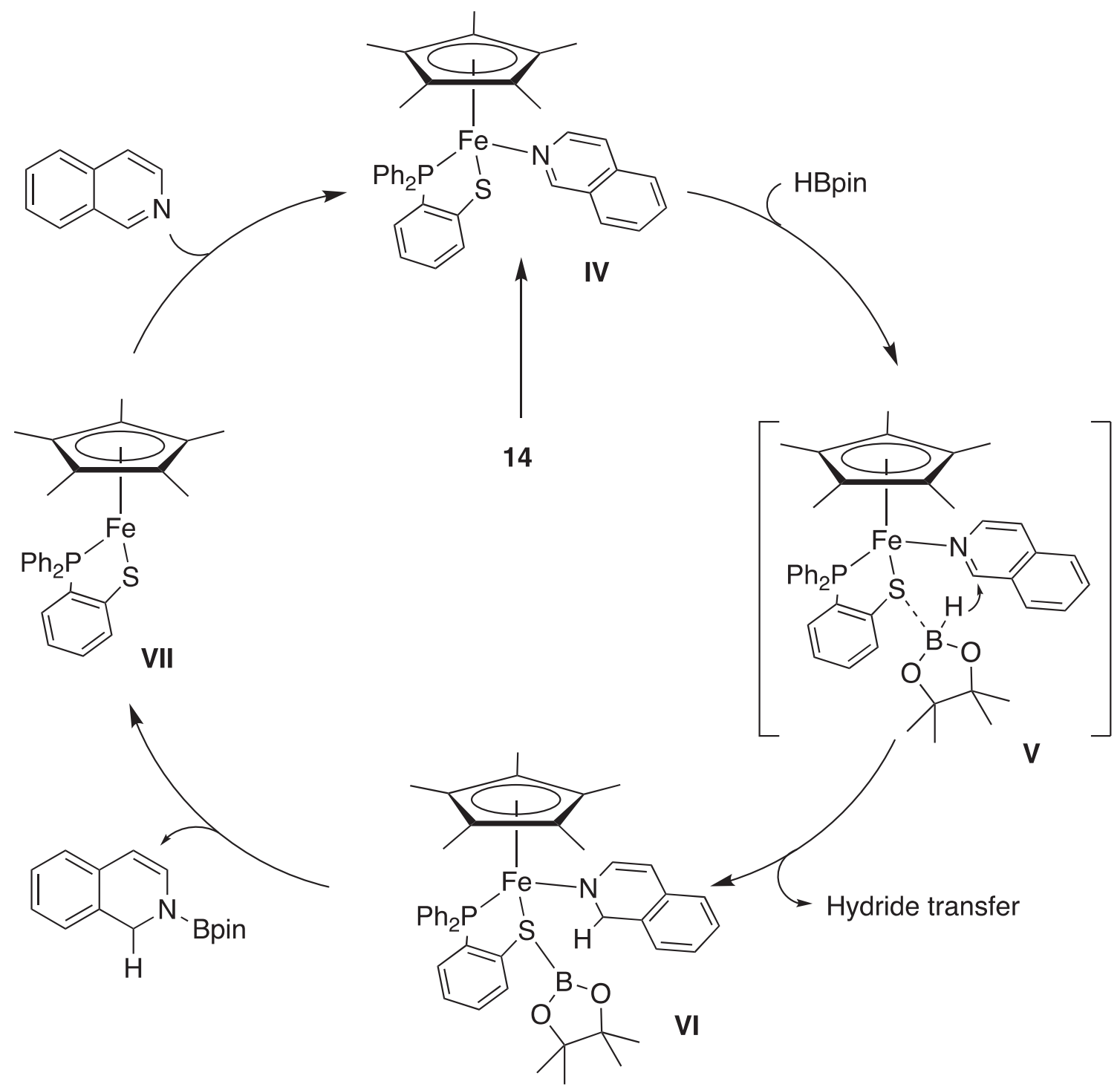

Scheme 13. Proposed catalytic cycle for hydroboration of isoquinoline by $\mathbf{1 4}$.

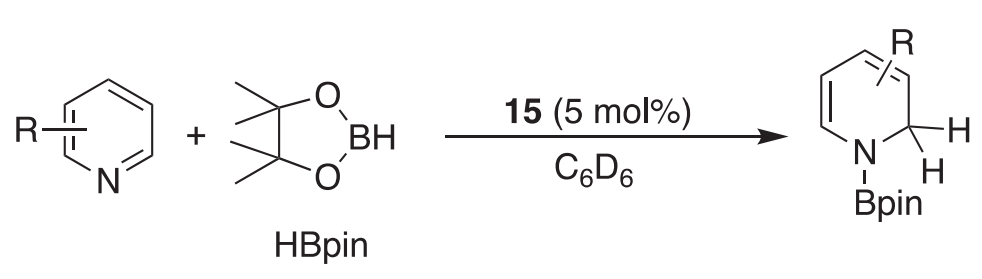

HBpin<smiles>Brc1ccccc1</smiles>

$93 \%\left(70 \mathrm{~h}, 70^{\circ} \mathrm{C}\right)$<smiles>Brc1cccnc1</smiles>

$93 \%(15 \mathrm{~min}, \mathrm{rt})$<smiles></smiles>

15<smiles>BN1CC=Cc2ccccc21</smiles>

$96 \%(1.2 \mathrm{~h}, \mathrm{rt})$<smiles>CC1(C)C=Cc2ccccc2N1c1ccccc1</smiles>

$13 \%\left(9 \mathrm{~d}, 70^{\circ} \mathrm{C}\right)$

Scheme 14. Hydroboration of $N$-heterocycles catalyzed by complex 15 . 


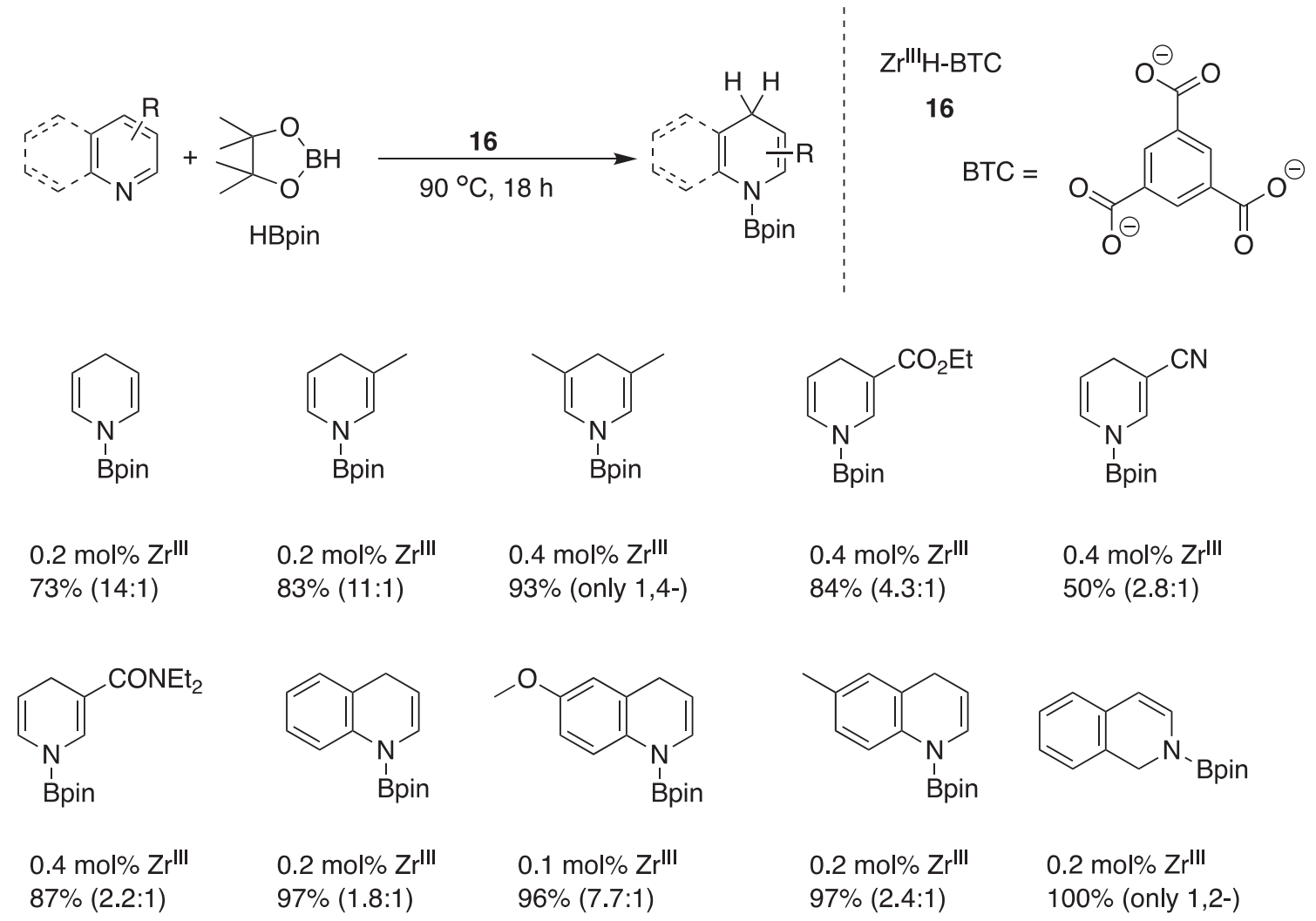

Scheme 15. Catalytic 1,4-hydroboration of pyridines and quinolines by 16. Ratio of 1,2- and 1,4-hydroboration products is given within parentheses.

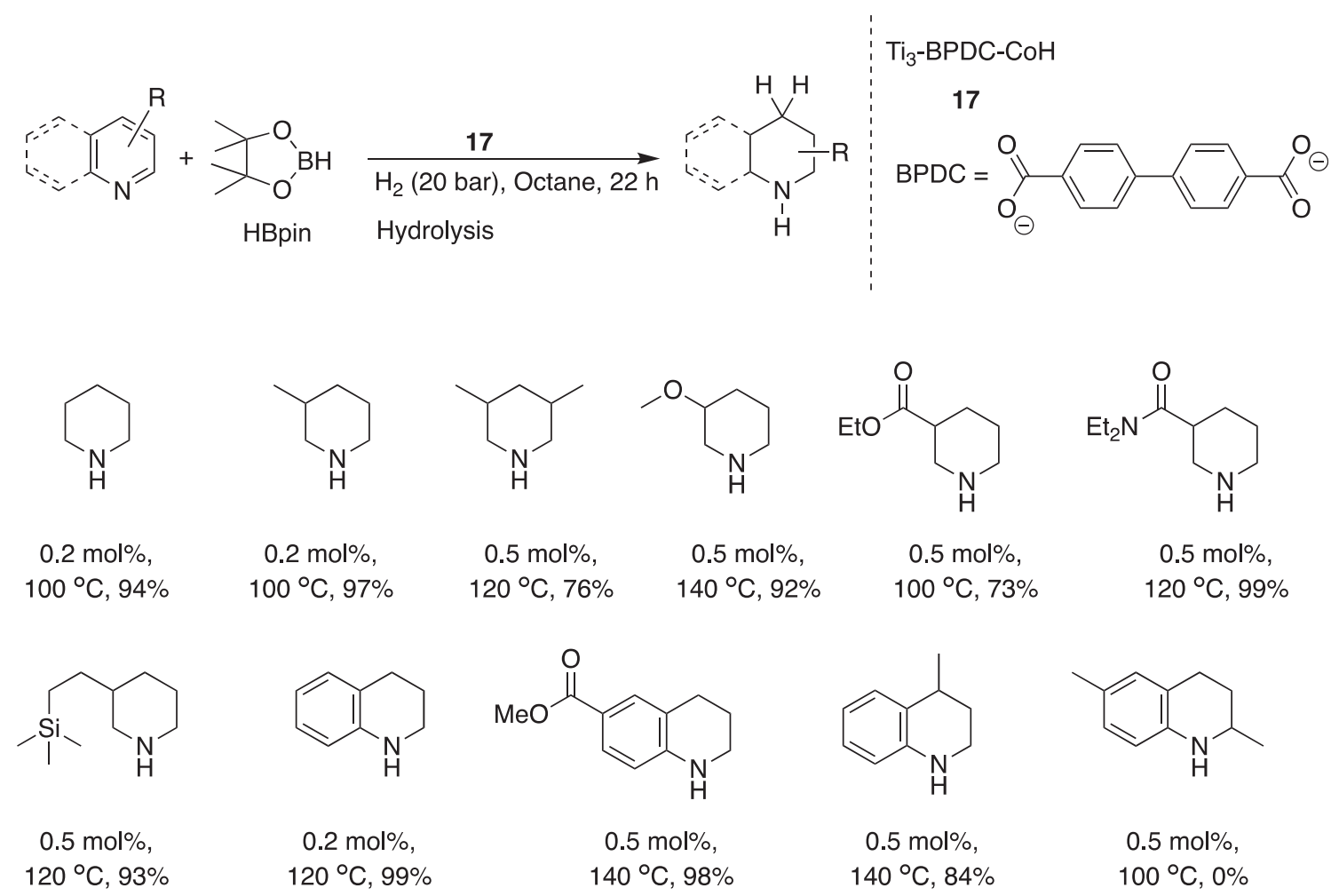

Scheme 16. Cascade hydroboration and hydrogenation of $N$-heteroarenes by $\mathbf{1 7}$. 


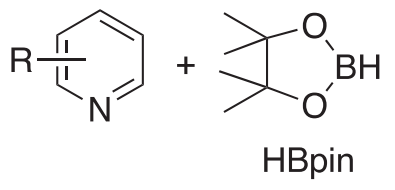

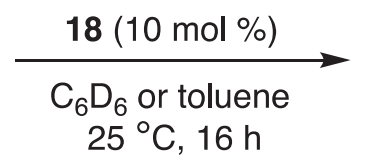

$25{ }^{\circ} \mathrm{C}, 16 \mathrm{~h}$<smiles>[R]C1C=CN(Br)C=C1</smiles>

1,4-

Yield (\%)<smiles>CC1=CN(B(O)c2ccccc2)C=CC1</smiles><smiles>Pc1ccccc1</smiles>

$41 \%(40), 60^{\circ} \mathrm{C}$

$75 \%(71)$<smiles>CN1C=CCC=C1Br</smiles>

Bpin

$0 \%$<smiles>N#CC1=CN(Br)C=CC1</smiles>

$99 \%(61)$<smiles>Pc1ccccc1</smiles>

$0 \%$<smiles>COC(=O)C1=CN([R6]OC(=O)O)C=CC1</smiles>

99\% (89)<smiles>CC1=C(C)NC=CC1</smiles>

Bpin

$77 \%(75)$<smiles>CB(c1c(C(F)(F)F)cc(C(F)(F)F)cc1C(F)(F)F)c1c(C(F)(F)F)cc(C(F)(F)F)cc1C(F)(F)F</smiles><smiles>C#CC1=CN(Br)C=CC1</smiles>

$99 \%(93)$<smiles>CC1=CC(C)NC(C)=C1</smiles>

Bpin

Scheme 17. Organoborane 18 catalyzed 1,4-regioselective hydroboration.

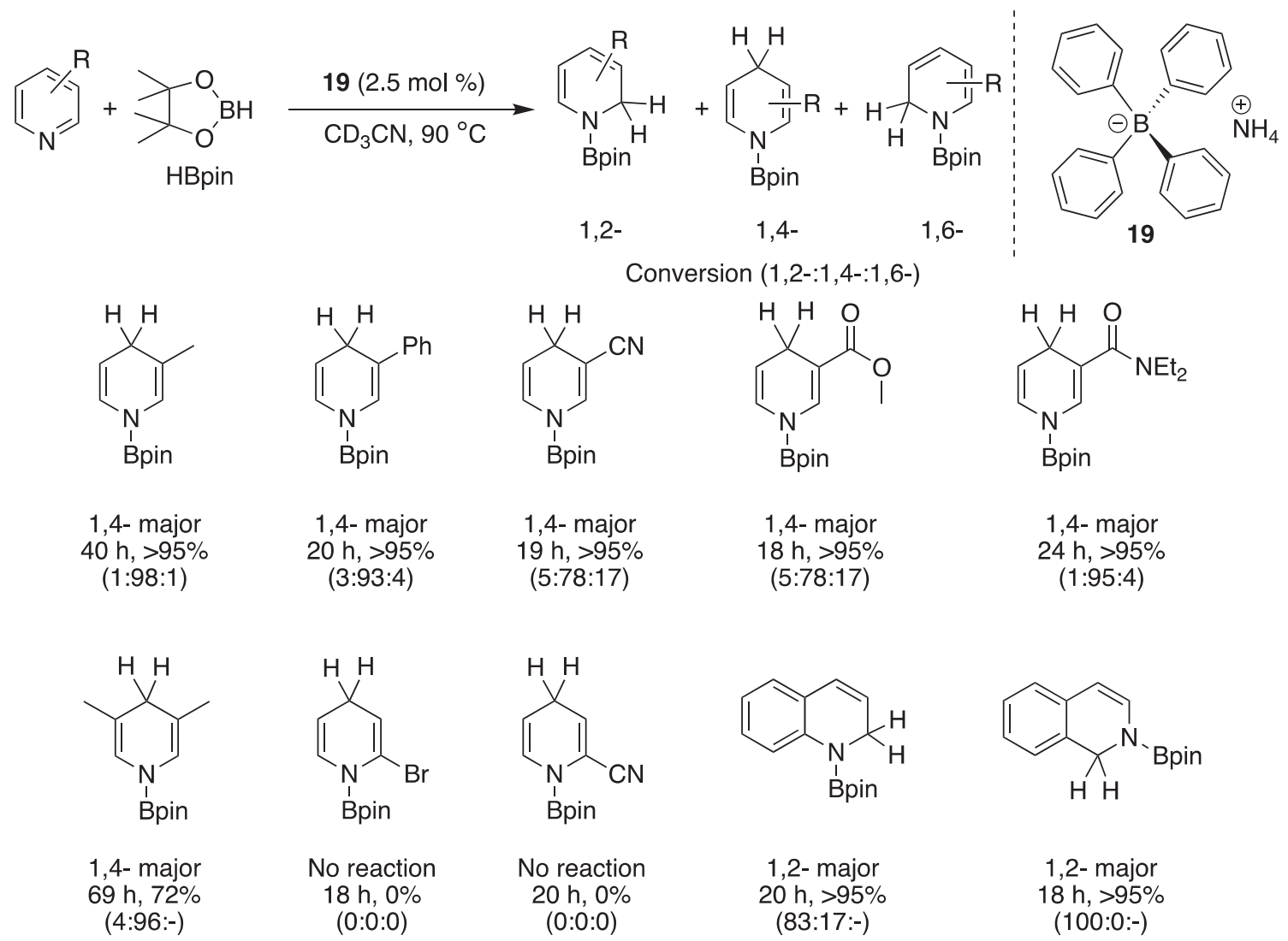

Scheme 18. Catalytic hydroboration of substituted $N$-heteroarenes by 19 . 
<smiles></smiles><smiles>CC(C)(C#N)O[Mg]</smiles>
$\mathrm{CD}_{3} \mathrm{CN}, \mathrm{rt}$

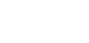

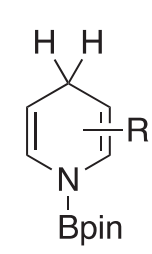

1,4-<smiles></smiles><smiles>Brc1ccccc1</smiles><smiles></smiles><smiles>CC1=CN(Br)C=C(C)C1</smiles$96 \%(91 \%), 12 \mathrm{~h}$ $99 \%(82 \%), 2 \mathrm{~h}$ $96 \%(88 \%), 12 \mathrm{~h}$

$91 \%(79 \%), 12 \mathrm{~h}$<smiles>CC(=O)C1=CN(Br)C=CC1</smiles>

$99 \%(90 \%), 1 \mathrm{~h}$<smiles>CN(C1=CN(B(c2ccccc2)c2ccccc2)C=CC1)c1ccccc1</smiles>
$99 \%, 1: 4,(78 \%), 14 \mathrm{~h}$<smiles>[R]C1=CCC=CN1[B]</smiles>

$\mathrm{R}=\mathrm{Br}, \mathrm{CN}$ No reaction<smiles>C1=Cc2ccccc2N(c2ccccc2)C=C1</smiles>

$95 \%, 1: 2,(88 \%), 4 \mathrm{~h}$

Scheme 19. Catalytic regioselective 1,4-hydroboration of $N$-heteroarenes by $\mathbf{2 0}$.

quinolines with methyl groups on different positions (3-,4-,6-,7-) and with different functional groups $(\mathrm{Cl}$, $\mathrm{OMe}, \mathrm{COOMe}$ ) as well as quinoxaline were all semihydrogenated to 1,2,3,4-tetrahydroquinolines in excellent yields with good selectivities.

\section{Hydroboration of heteroarenes catalyzed by p- block elements}

A bulky organoborane $\mathrm{ArF}_{2} \mathrm{BMe}(\mathrm{ArF}=2,4,6$ tris(trifluoromethyl)phenyl) and pyridine in solution form a frustrated Lewis pair, which was able to catalyze regioselective 1,4-hydroboration of pyridines under mild condition (Scheme 17). ${ }^{27}$ Under the optimized condition and limitation of the protocol was investigated. Electron donating substituent at meta position decrease the efficiency of the catalyst, while electron-withdrawing substituents provided good to excellent yields. Bromo and iodo substituents, which are prone to undergo dehalogenation, were found to be compatible with the catalytic system. Moreover, strongly coordinating cyano group did not impede the reaction. Remarkably, the ethynyl and cyano moieties, which are prone to undergo reduction, remained unaffected under the reaction conditions. However, the protocol is susceptible to the steric hindrance at ortho position leading to no formation of the desired product.

Commercially available ammonium salt $\mathrm{NH}_{4} \mathrm{BPh}_{4}$ (19), reacts with a pyridine-activated pinacolborane species to generate a boronium cation, which acts as the active catalyst for 1,4-regioselective hydroboration of pyridines in polar solvents. ${ }^{28}$ The proposed active boronium species in this reaction, $\operatorname{pinBPy}_{2} \mathrm{BPh}_{4}$, was isolated and characterized. Upon optimization of the catalytic method for pyridine, the substrate scope of the reaction was explored (Scheme 18). The reaction is amenable to various functionalities including dehalogenation prone bromide functionality, Lewis basic and reducible cyano, ester, and amide substituents in the meta-position. Furthermore, the hydroboration of 3,5-lutidine, a sterically demanding substrate could be achieved with excellent regioselectivity (1,2-:1,4- product ratio of 4:96). However, the regioselectivity of this transformation is susceptible to 


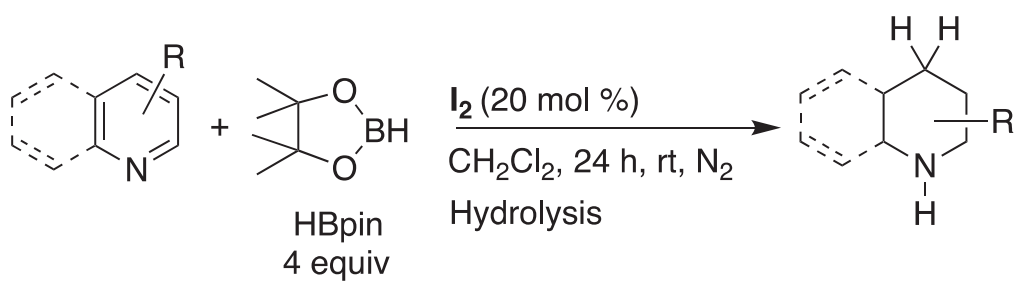<smiles>c1ccc2c(c1)CCCN2</smiles>

$91 \%$<smiles>Cc1ccc2c(c1)CCCN2</smiles>

$84 \%$<smiles>c1ccc(C2CCc3ccccc3N2)cc1</smiles>

$84 \%$ toluene, $100{ }^{\circ} \mathrm{C}$<smiles>CC1CCc2ccccc2N1</smiles>

$81 \%$<smiles>CC1CNc2ccccc2C1</smiles>

$84 \%$<smiles>Cc1cccc2c1NCCC2</smiles>

$89 \%$<smiles>O=[N+]([O-])c1cccc2c1CCCN2</smiles>

$82 \%$<smiles>CC1CCNc2ccccc21</smiles>

$76 \%$<smiles>COc1ccc2c(c1)CCCN2</smiles>

$85 \%$

toluene, $100{ }^{\circ} \mathrm{C}$<smiles>COC(=O)c1ccc2c(c1)CCCN2</smiles><smiles>c1ccc2c(c1)CCNC2</smiles>

$88 \%$<smiles>c1cnc2c3c(ccc2c1)CCCN3</smiles>

$83 \%$<smiles>Cc1cccc2c1CCCN2</smiles>

$86 \%$<smiles>C=CCOc1cccc2c1NCCC2</smiles>

$89 \%$<smiles>Fc1cccc2c1NCCC2</smiles>

$87 \%$<smiles>Clc1ccc(CCC2CCc3ccccc3N2)cc1</smiles>

$87 \%$

Scheme 20. Iodine-catalyzed tandem hydrogenation of $N$-heteroarenes.

the changing polarity of the solvent, where polar solvents (acetonitrile, 1,2-difluorobenzene, pyridine) favor selective 1,4-hydroboration.

Enhanced Lewis acidity of the $\mathrm{P}$ center in the form of phosphenium cation acts as an efficient catalyst for hydride transfer in the hydroboration reaction of $\mathrm{N}$ heteroarenes (Scheme 19). ${ }^{29}$ The method involves $N$ heterocyclic phosphenium triflates (NHPOTf) 20 as efficient catalysts for the regio- and chemoselective hydroboration of pyridines with good functional group tolerance. During the progress of the reaction, the formation of boronium salt $\left[(\mathrm{Py})_{2} \cdot\right.$ Bpin $] \mathrm{OTf}$ and concomitant hydride abstraction from HBpin by $\mathbf{2 0}$ is proposed as the key steps involved in the reaction mechanism. When subjected to the optimized reaction condition various substrates containing methyl, phenyl, ester, acetyl, cyano, and amide groups afforded the corresponding 1,4-regioselective products in high yields.

Employing NHC-boranes and sub-stoichiometric $\mathrm{I}_{2}$ as catalyst $\mathrm{C}_{2}$-borylation of indoles was achieved. ${ }^{30}$ Substantial evidence also demonstrates a dramatic impact of $\mathrm{I}_{2}$ as an additive on hydrogenation of $\mathrm{N}$ heteroarenes. $^{31}$ Based on these studies Chang and coworkers have investigated the role of iodine as the catalyst for tandem hydrogenation of $\mathrm{N}$-heteroarenes 


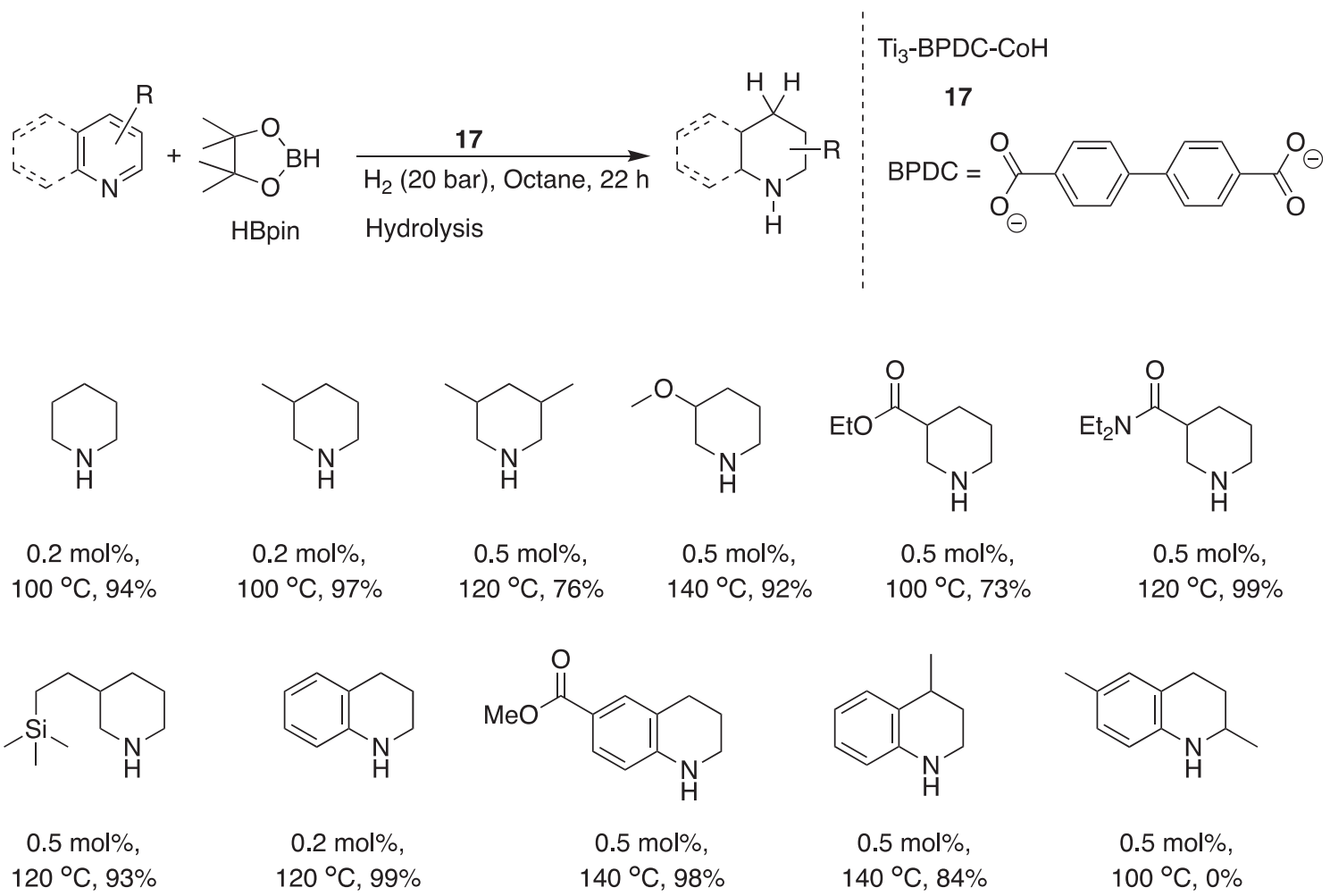

Scheme 21. Dinuclear magnesium hydride catalyzed hydroboration of $N$-heteroarenes.

using HBpin as reducing agent. ${ }^{32}$ With the optimized reaction conditions the substrate scope of $N$ heteroarenes was investigated (Scheme 20). As these results showed, the products could be obtained in good to high isolated yields. Substituents containing different functionality have less impact on the yields. When subjected to the catalytic condition, isoquinoline, quinoxaline, phenanthroline also underwent the reaction with similar efficiency.

\section{Hydroboration of heteroarenes catalyzed by s- block elements}

A dinuclear magnesium hydride complex was developed by Harder and coworkers to investigate hydroboration of $\mathrm{N}$-heteroarenes. ${ }^{33}$ The complex (21) contains a N-N bond $\left[\mathrm{NN}=\left[\left(2,6-{ }^{i} \mathrm{Pr}_{2} \mathrm{C}_{6} \mathrm{H}_{3}\right)-\right.\right.$ $\left.\left.\mathrm{NC}(\mathrm{Me}) \mathrm{CHC}(\mathrm{Me}) \mathrm{N}-]_{2}\right)\right]$, which affects differently during catalysis than the $p$-phenylene spacer $(\mathrm{PARA}=$ $\left.\left[\left(2,6-\quad{ }^{i} \mathrm{Pr}_{2} \mathrm{C}_{6} \mathrm{H}_{3}\right) \mathrm{NC}(\mathrm{Me}) \mathrm{C}(\mathrm{H}) \mathrm{C}(\mathrm{Me}) \mathrm{N}_{2}-\left(p-\mathrm{C}_{6} \mathrm{H}_{4}\right)\right)\right)$ connected dinuclear magnesium hydride complexes with $\beta$-diketiminate ligands. The nature of the bridge strongly influences the reactivity of the magnesium complex with $\mathrm{N}$-heteroarenes. The PARA-spacer connected complex shows comparable reactivity with that of the mononuclear $\beta$-diketiminate magnesium hydride complex. The formation of 1,4-DHP (DHP = dihydrpyridine) upon heating the reaction mixture from the mixture of 1,2-DHP/1,4-DHP was anticipated due to the thermodynamic stability of the products. While the dinuclear magnesium hydride complex (21) directly coupled with $\beta$-diketiminate ligands (NN) reacts contrarily with pyridine to form exclusively the 1,2-DHP products (Scheme 21). This unusual difference of reactivity probably arises due to the secondary intramolecular interactions from extended $\mathrm{C}-\mathrm{H} \cdots \mathrm{C} \pi-$ interactions and $\pi$-stacking interactions.

1,4-Dihydropyridyl complexes of magnesium were found to have efficient reactivity towards pyridine hydroboration, reported by Okuda and coworkers. ${ }^{34}$ Synthesis of complex 22 was achieved starting from magnesium bis(triphenylsilyl) $\quad\left[\mathrm{Mg}\left(\mathrm{SiPh}_{3}\right)_{2}(-\right.$ $\mathrm{THF})_{2}$ ] THF and pyridine, while complex 23 and $\mathbf{2 4}$ was prepared by reacting $\left(\mathrm{Me}_{3} \mathrm{TACD}\right) \mathrm{MgSiPh}_{3}$ and $\left(\mathrm{Me}_{3} \mathrm{TACD} \cdot \mathrm{Al}^{i} \mathrm{Bu}_{3}\right) \mathrm{MgSiPh}_{3} \quad\left[\left(\left(\mathrm{Me}_{3} \mathrm{TACD}\right) \mathrm{H}=\right.\right.$ $\mathrm{Me}_{3}$ [12] $\mathrm{aneN}_{4}$ : 1,4,7 trimethyl-1,4,7,10-tetraazacyclododecane)] with pyridine. The catalytic behavior of these complexes towards hydroboration of substituted pyridines is summarized in Table 1.

Hill and coworkers have described the facile reaction of catalytic $\beta$-diketiminato $n$-butylmagnesium complex with pinacolborane in the presence of pyridine derivatives to provide facile borylated dihydropyridines 
Table 1. Reactivity comparison of different magnesium complexes in pyridine hydroboration.

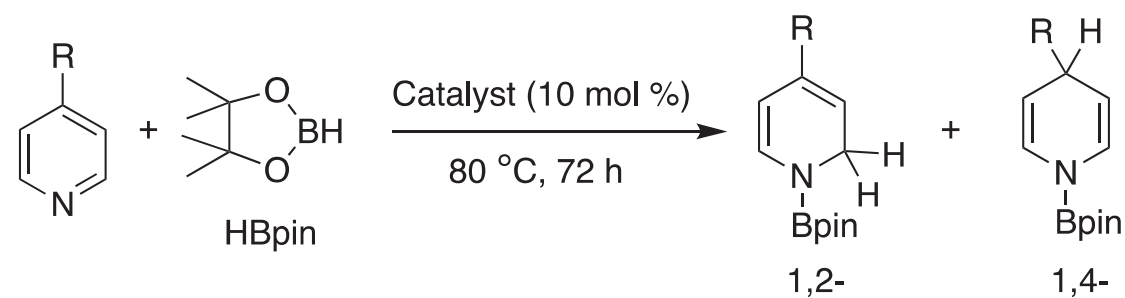

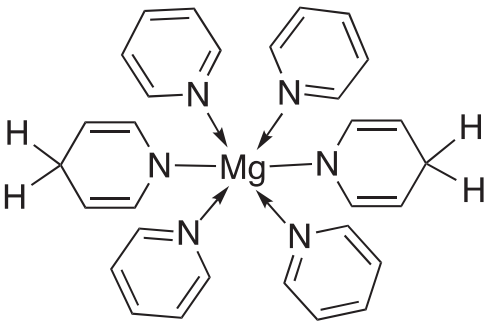

22

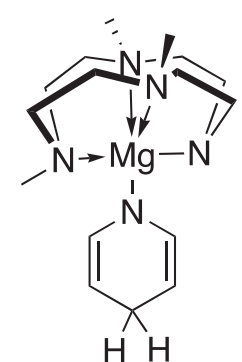

23

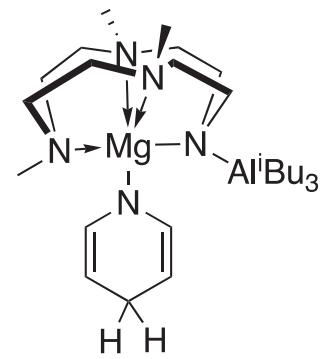

24

\begin{tabular}{lclcc}
\hline Entry & Catalyst & \multicolumn{1}{c}{$\mathrm{R}$} & $1,2-: 1,4$-isomers [\%] & Conversion [\%] $^{a}$ \\
\hline 1 & $\mathbf{2 2}$ & $\mathrm{H}$ & $3: 97$ & 52 \\
2 & $\mathbf{2 3}$ & $\mathrm{H}$ & $4: 96$ & 74 \\
$3^{b}$ & $\mathbf{2 3}$ & $\mathrm{H}$ & $10: 90$ & 68 \\
4 & $\mathbf{2 3}$ & tert-Butyl & $27: 73$ & 75 \\
$5^{b, c}$ & $\mathbf{2 3}$ & tert-Butyl & $45: 53$ & 75 \\
6 & $\mathbf{2 4}$ & H & $3: 97$ & 70 \\
\hline
\end{tabular}

${ }^{a}$ Determined by ${ }^{1} \mathrm{H}$ NMR spectroscopy (hexamethylbenzene as an internal standard in THF-d8).

${ }^{b}$ Performed in benzene-d6.

${ }^{c}$ PinB-1,4-DHP is also detected from the release of pyridine by $\mathbf{2 3}$.

(Scheme 22). ${ }^{35}$ The catalytic protocol was subjected to a wide range of monocyclic and fused-ring pyridine derivatives and the progress of the reaction is proposed to proceed via a sequence of pyridine dearomatization and sigma bond metathesis steps. However, the method was not successful towards catalytic hydrosilylation, while more Lewis acidic boron center of pinacolborane eventually leads to more effective access to the $\mathrm{Mg}-\mathrm{N}$ bond during $\mathrm{Mg}-\mathrm{N} / \mathrm{B}-\mathrm{H}$ bond metathesis. Under the optimized condition, employing catalytic quantity of $\mathbf{2 5}$ (5-10 $\mathrm{mol} \%$ ) the reaction proceeded smoothly leading to the formation of desired products in good to excellent yields. The reactions with quinoline and isoquinoline also proceeded effectively at room temperature. No catalytic hydroboration was observed for strongly coordinating bipyridine moiety. The catalytic system was not tolerant towards aldehyde and ester functionalities.
Parkin and coworkers have developed a synthetic route to attain the magnesium carbatrane catalyst $\left[\right.$ Tism $\left.^{\text {PriBenz }}\right] \mathrm{MgH}$ (26) [Tism $^{\text {PriBenz }}=\operatorname{tris}[(1$-isopropylbenzimidazol-2-yl)-dimethylsilyl)]methyl] via the reaction of $\left[\mathrm{Tism}^{\text {PriBenz }}\right] \mathrm{MgMe}$ with $\mathrm{PhSiH}_{3}{ }^{36}$ During investigation of the catalytic properties, it revealed that $\left[\right.$ Tism $\left.^{\text {PriBenz }}\right] \mathrm{MgH}$ is a catalyst for hydrosilylation and hydroboration of styrene to afford the Markovnikov products; also hydroboration of carbodiimides and pyridines can be achieved efficiently. The hydroboration reaction of pyridines provided a mixture of 1,4- and 1,2isomers, of which the 1,4-isomer is obtained predominantly. When subjected to the catalytic condition, a $7: 1$ ratio of 1,4 to 1,2 isomers is obtained at $60{ }^{\circ} \mathrm{C}(10 \%$ catalyst loading), while an $11: 1$ ratio is obtained at $100{ }^{\circ} \mathrm{C}$ (Scheme 23).

Alkoxide base $\mathrm{KO}^{t} \mathrm{Bu}$ catalyzed dearomative hydroboration was demonstrated by Chang and co- 


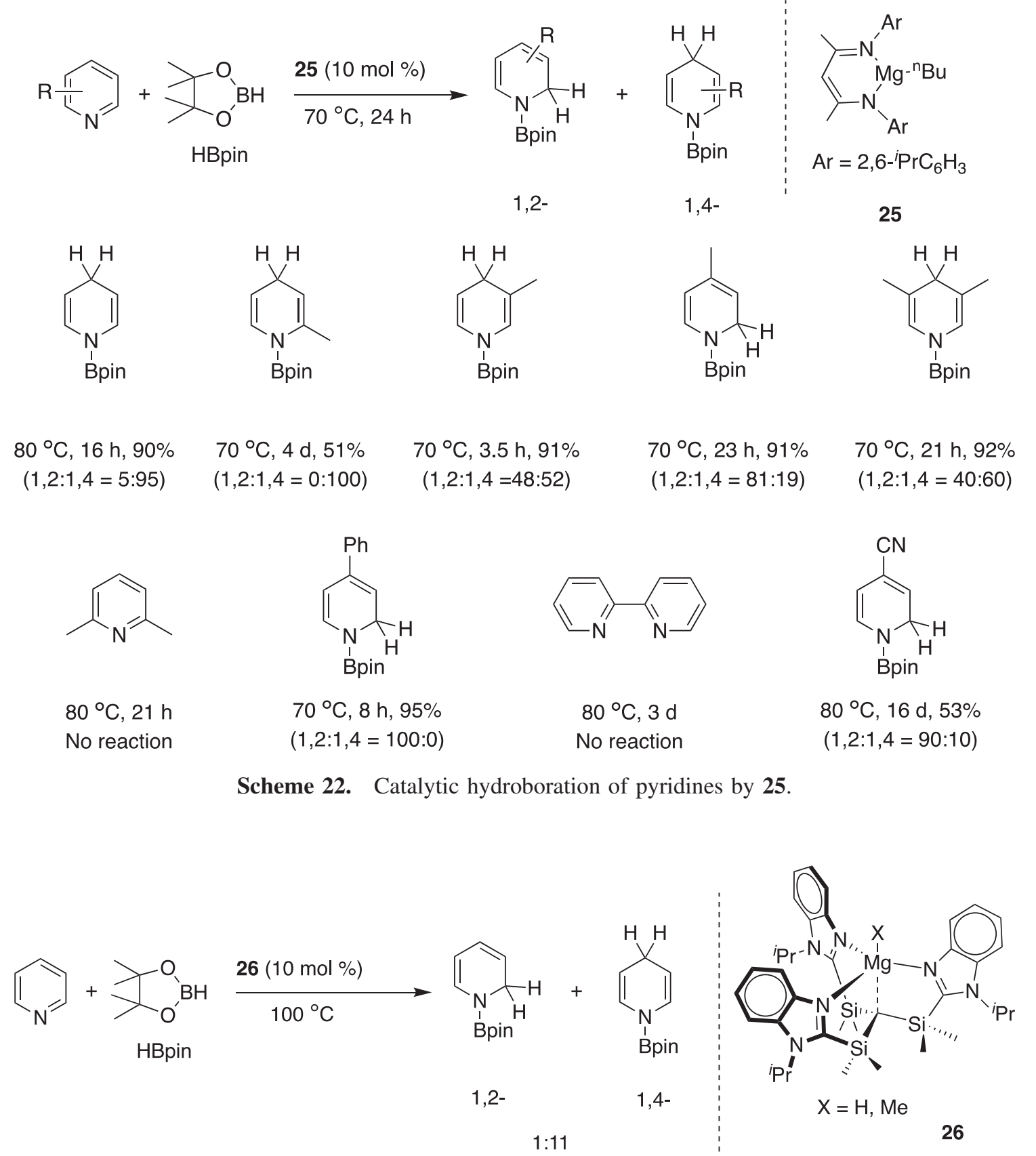

Scheme 23. Mg-carbatrane catalyst for pyridine hydroboration.

workers (Scheme 24). ${ }^{37}$ Detailed mechanistic investigations revealed the formation of rapid pre-equilibrium between several borohydride species with $\mathrm{KO}^{t} \mathrm{Bu}$, and concomitant formation of the initial adduct of pyridine with in-situ generated $\mathrm{BH}_{3}$ species, to which selective transfer of borohydride breaks aromaticity of pyridine. It is also found that 1,4-dihydropyridyl borohydride is a prevalent resting state. Addition of 18-crown-6 ether significantly influenced the efficiency of the catalyst, suggesting an ion-pair induced outer sphere pathway for the reaction progress. When implemented the optimized catalytic condition, a wide array of substrates including substituted pyridines, quinolines, isoquinolines, pyrazines, quinoxalines, and imidazoles underwent efficient reaction with reasonable regioselectivity.

Very recently, a regioselective hydroboration of $\mathrm{N}$-heteroarenes with pinacolborane catalyzed by potassium hydride was developed by Zhang and coworkers. ${ }^{38}$ This unique protocol leads to regioselective 1,2-hydroboration of quinolines, while pyridines displayed regioselective 1,4-hydroboration under the standard set 


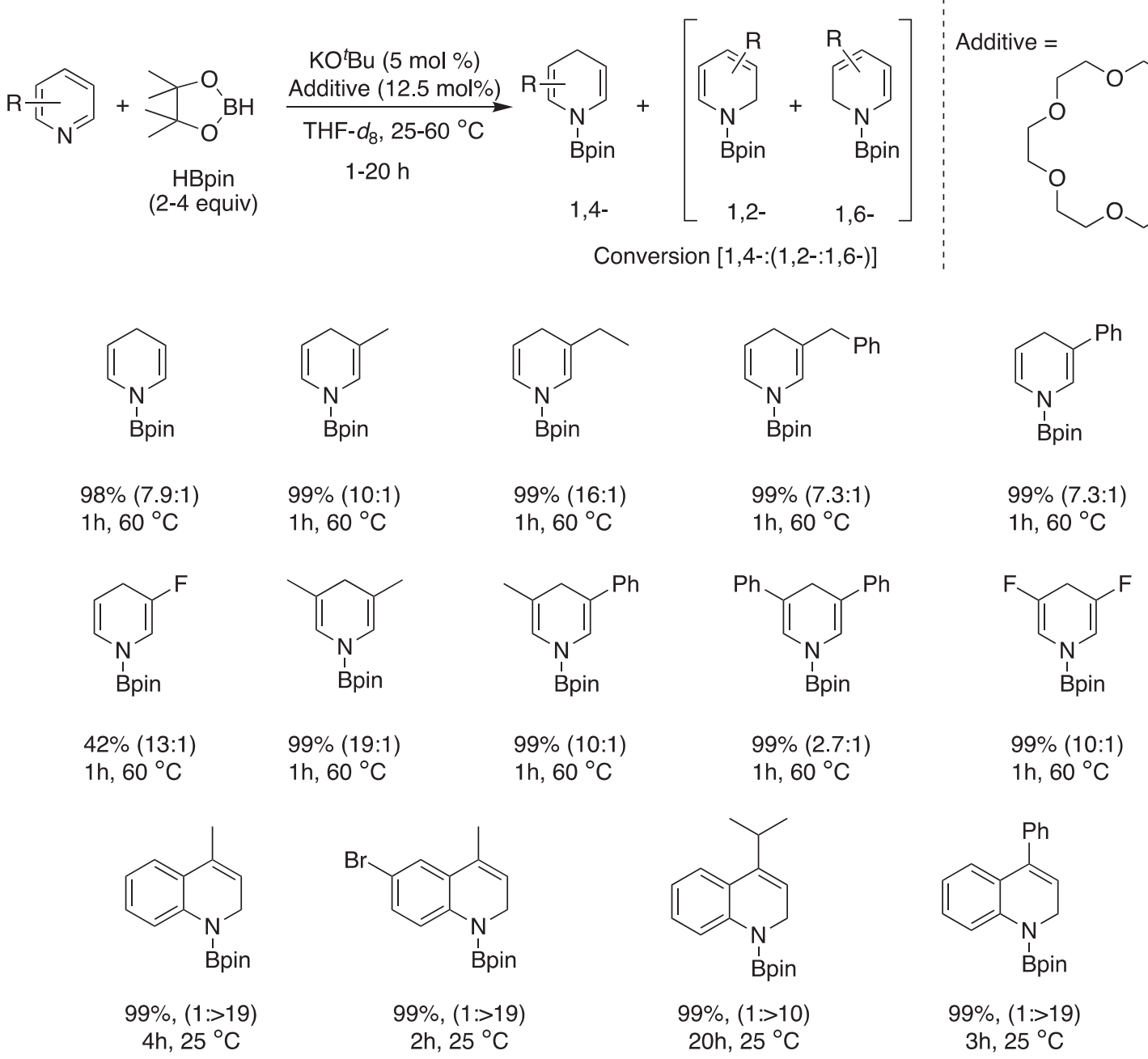

Scheme 24. Base catalyzed hydroboration of $N$-heteroarenes.

of reaction conditions. Experimental and kinetic investigations suggest that quinolines react with HBpin much faster with the corresponding intermediate leading to the 1,2-regioisomer rather than undergoing relatively slow isomerization to generate the 1,4-regioisomer. When subjected to the catalytic condition, a range of quinolines and pyridine derivatives displayed distinct reactivities to provide 1,2- and 1,4-regioisomers, respectively (Scheme 25). However, the method suffers steric hindrance from 2- and 8-substituted quinolines.

\section{Different modes of bond activation and the origin of selectivity}

The catalytic dearomative hydroboration of heteroaromatic compounds proceeds through various bond activation processes. However, these bond-activation modes can be broadly classified as three different types. Among them, the dominant mode of activation is the insertion of metal (M) into " $\mathrm{B}-\mathrm{H}$ " bond to form "B-M-H" species. Subsequently, metal hydrides undergo migratory insertion to the coordinated " $\mathrm{C}=\mathrm{N}$ " bond (part of ligated heteroaromatic compound), which provides the corresponding desired product. ${ }^{13,15}$ Another efficient class of bond activation is via metal-ligand cooperation, where " $\mathrm{B}-\mathrm{H}$ " bond activation takes place by active participation of metal center and ligated non-innocent ligand in which the boron gets coordinated to the metal and the proton is accepted by the basic ligand site. ${ }^{19-21}$ Finally, recent studies have demonstrated that base can catalyze this process, which is mainly initiated by fast formation of borohydride adducts upon treating borane source with base and usually governed by Lewis acid-base interactions. ${ }^{37}$

The origin of regioselectivity is predominantly influenced by steric and electronic factors on substrates as well as at the metal center. When electrondonating and sterically demanding phosphine ligands 

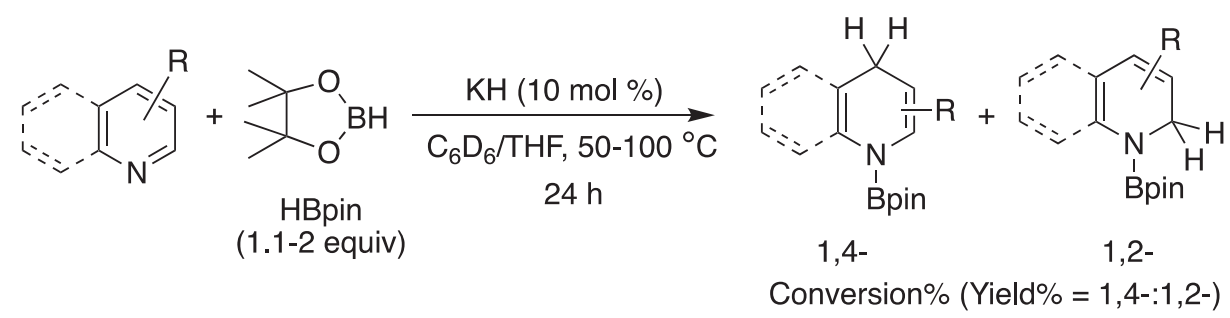

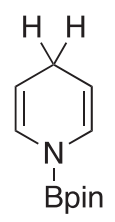

$100(94: 6)$

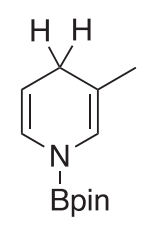

95 (95:0)<smiles>CCC1=CN(Cc2ccccc2)C=CC1</smiles>

95 (95:0)<smiles>CC1=CC(Nc2ccccc2)c2ccccc21</smiles>

99 (0:99)<smiles>Brc1ccc2c(c1)C=CCC2Nc1ccccc1</smiles>

99 (96:03)<smiles>BrC1=CN(Cc2ccccc2)C=CC1</smiles>

$0(0: 0)$<smiles>Cc1cccc2c1C=CCC2Nc1ccccc1</smiles>

$100(85: 15)$<smiles>Brc1ccccc1</smiles>

96 (96)

$97(95: 2)$ 95 (90:05)

Scheme 25. Potassium-catalyzed hydroboration of $N$-heteroarenes.

were introduced at the metal center, selectivity drastically improved to provide either 1,2 or 1,4-selective hydroboration depending upon the type of catalyst and its influential coordination environment. ${ }^{15,16}$ During the transfer of hydride to the coordinated substrates steric influence plays a crucial role in determining the regioselectivity. ${ }^{15}$ Notably, the regioselectivity of the dihydropyridine products is sensitive to the substituents on the precursor, particularly when substituents are present in ortho positions. ${ }^{22}$ As observed by Marks and co-workers, there is also significant bonding interactions between substituent (particularly halogen) and pyridine " $\mathrm{CH}_{2}$ " of ortho position during the turnover determining transition states, which greatly influences the regioselectivity of 3-substituted pyridine hydroboration. ${ }^{13}$ It is important to note that hydride transfer occurring directly from the metal center, leads to greater selectivity. On the contrary, when transfer of hydride takes place directly from borane to pyridine without the formation of any intermediate metal hydride complex, both 1,2- and 1,4- regioisomers are formed. ${ }^{33}$ For MOF catalysts, usually the substrate binding to a specific site and also the shape of the catalyst determines the selectivity. ${ }^{26}$

\section{Conclusions}

In summary, this review elaborates different catalytic protocols developed for the hydroboration of heteroarenes and discusses various catalysts employed for this purpose across the periodic table. Challenging and regioselective dearomatization of heteroarenes was achieved with good to excellent selectivity. Dearomatized heteroarenes play a pivotal role in their potential applications in various dimensions of synthetic chemistry. This review also indicates that while heavier transition metal catalysts provide superior catalysis with very high selectivity, careful design of early metal complexes and simple organic compounds 
can also function as potential catalysts for this transformation. The different mode of bond activation and factors influencing the regioselectivity are also summarized. Achieving selectivity in these transformations is crucial; separation of regioisomers is complicated as the hydroboration products of the heteroaromatic compounds are highly sensitive to moisture and less stable. Thus, catalytic systems that exhibit high or exclusive selectivity to any one of the regioisomers with high efficiency can be useful in synthesis. Therefore, this review enables the summary of the topic and allows readers to comprehend the established protocols in the direction of further developing inventive catalytic methodologies.

\section{Acknowledgement}

CG thanks SERB New Delhi (EMR/2016/002517), DAE and NISER for financial support.

\section{References}

1. (a) Pollak N, Dölle C and Ziegler M 2007 The power to reduce: Pyridine nucleotides-small molecules with a multitude of functions Biochem. J. $\mathbf{4 0 2}$ 205; (b) Eisner U and Kuthan J 1972 Chemistry of dihydropyridines Chem. Rev. 72 1; (c) Stout evidence and Meyers A I 1982 Recent advances in the chemistry of dihydropyridines Chem. Rev. 82 223; (d) Sliwa W 1986 The reactivity of N-substituted pyridinium salts Heterocycles 24 181; (e) Lavilla R J 2002 Recent developments in the chemistry of dihydropyridines Chem. Soc. Perkin Trans. 11141

2. (a) Rueping M, Dufour J and Schoepke F R 2011 Advances in catalytic metal-free reductions: from bioinspired concepts to applications in the organocatalytic synthesis of pharmaceuticals and natural products Green Chem. 13 1084; (b) Ouellet S G, Walji A M and Macmillan D W C 2007 Enantioselective organocatalytic transfer hydrogenation reactions using Hantzsch esters Acc. Chem. Res. 401327

3. Edraki N, Mehdipour A R, Khoshneviszadeh M and Miri R 2009 Dihydropyridines: evaluation of their current and future pharmacological applications Drug Discov. Today 141058

4. Satoh N, Akiba T, Yokoshima S and Fukuyama T 2007 A practical synthesis of (-)-oseltamivir Angew. Chem. Int. Ed. 465734

5. (a) Cozzi P, Carganico G, Fusar D, Grossoni M, Menichincheri M, Pinciroli V, Tonani R, Vaghi F and Salvati P 1993 Imidazol-1-yl and pyridin-3-yl derivatives of 4-phenyl-1,4-dihydropyridines combining $\mathrm{Ca}^{2+}$ antagonism and thromboxane $\mathrm{A} 2$ synthase inhibition $J$. Med. Chem. 36 2964; (b) Kumar P P, Stotz S C, Paramashivappa R, Beedle A M, Zamponi G W and Rao A S 2002 Synthesis and evaluation of a new class of nifedipine analogs with T-type calcium channel blocking activity Mol. Pharmacol. 61649

6. Bull J A, Mousseau J J, Pelletier G and Charette A B 2012 Synthesis of pyridine and dihydropyridine derivatives by regio- and stereoselective addition to N-activated pyridines Chem. Rev. 1122642

7. (a) Adkins H, Kuick L F, Farlow M and Wojcik B 1934 Hydrogenation of derivatives of pyridine $J$. Am. Chem. Soc. 56 2425; (b) Freifelder M and Stone G R 1961 Reductions with ruthenium. II. Its use in the hydrogenation of pyridines ${ }^{1} \mathrm{~J}$. Org. Chem. 26 3805; (c) Lunn G and Sansone E B 1986 Facile reduction of pyridines with nickel-aluminum alloy J. Org. Chem. 51 513; (d) Takasaki M, Motoyama Y, Higashi K, Yoon S-H, Mochida I and Nagashima H 2007 Ruthenium nanoparticles on nano-Level - controlled carbon supports as highly effective catalysts for arene hydrogenation Chem. Asian J. 2 1524; (e) Buil M L, Esteruelas M A, Niembro S, Olivan M, Orzechowski L, Pelayo C and Vallribera A 2010 Dehalogenation and hydrogenation of aromatic compounds catalyzed by nanoparticles generated from rhodium bis(imino)pyridine complexes Organometallics 29 4375; (f) Glorius F 2005 Asymmetric hydrogenation of aromatic compounds Org. Biomol. Chem. 34171

8. Fowler, F. W. 1972 Synthesis of 1,2- and 1,4-dihydropyridines J. Org. Chem. 371321

9. (a) Hao L, Harrod J F, Lebuis A-M, Mu Y, Shu R, Samuel E and Woo H-G 1998 Homogeneous catalytic hydrosilylation of pyridines Angew. Chem. Int. Ed. 37 3126; (b) Harrod J F, Shu R, Woo H G and Samuel E 2001 Titanocene(III) catalyzed homogeneous hydrosilyation-hydrogenation of pyridines Can. J. Chem. 79 1075; (c) Gutsulyak D V, van der Est A and Nikonov G I 2011 Facile catalytic hydrosilylation of pyridines Angew. Chem. Int. Ed. 50 1384; (d) Königs C D F, Klare H F T and Ostreich M 2013 Catalytic 1,4Selective hydrosilylation of pyridines and benzannulated congeners Angew. Chem. Int. Ed. 5210076

10. Oshima K, Ohmura T and Suginome M 2011 Palladium-catalyzed regioselective silaboration of pyridines leading to the synthesis of silylated dihydropyridines $J$. Am. Chem. Soc. 1337324

11. Daley E N, Vogels C M, Geier S J, Decken A, Doherty S and Westcott S A 2015 The phosphinoboration reaction Angew. Chem. Int. Ed. 542121

12. Liu H, Khononov M and Eisen M S 2018 Catalytic 1,2regioselective dearomatization of $\mathrm{N}$-heteroaromatics via a hydroboration ACS Catal. 83673

13. Dudnik A S, Weidner V L, Motta A, Delferro M and Marks T Z 2014 Atom-efficient regioselective 1,2dearomatization of functionalized pyridines by an earth-abundant organolanthanide catalyst Nat. Chem. 6 1100

14. Ji P, Sawano T, Lin Z, Urban A, Boures D and Lin W 2016 Cerium-hydride secondary building units in a porous metal-organic framework for catalytic hydroboration and hydrophosphination J. Am. Chem. Soc. 138 14860

15. Oshima K, OhmuraT and Suginome M 2012 Regioselective synthesis of 1,2-dihydropyridines by rhodium- 
catalyzed hydroboration of pyridines J. Am. Chem. Soc. 1343699

16. Kaithal A, Chatterjee B and Gunanathan C 2016 Ruthenium-catalyzed regioselective 1,4-hydroboration of pyridines Org. Lett. 183402

17. (a) Kaithal A, Chatterjee B and Gunanathan C 2015 Ruthenium catalyzed selective hydroboration of carbonyl compounds Org. Lett. 17 4790; (b) Chatterjee B and Gunanathan C 2014 Ruthenium catalyzed selective hydrosilylation of aldehydes Chem. Commun. 50 888; (c) Kaithal A, Chatterjee B and Gunanathan C 2016 Ruthenium-catalyzed selective hydroboration of nitriles and imines J. Org. Chem. 81 11153; (d) Kisan S, Krishnakumar V and Gunanathan C 2017 Ruthenium-catalyzed anti-Markovnikov selective hydroboration of olefins ACS Catal. 7 5950; (e) Kisan S, Krishnakumar V and Gunanathan C 2018 Rutheniumcatalyzed deoxygenative hydroboration of carboxylic acids ACS Catal. 84772

18. Tamang S R, Singh A, Unruh D K and Findlater M 2018 Nickel-catalyzed regioselective 1,4-hydroboration of N-heteroarenes ACS Catal. 86186

19. (a) Gunanathan C and Milstein D 2011 Metal-ligand cooperation by aromatization- dearomatization: A new paradigm in bond activation and "green" catalysis Acc. Chem. Res. 44 588; (b) Morris R H 2015 Exploiting metal-ligand bifunctional reactions in the design of iron asymmetric hydrogenation catalysts Acc. Chem. Res. 48 1494; (c) Zell T and Milstein D 2015 Hydrogenation and dehydrogenation iron pincer catalysts capable of metal-ligand cooperation by aromatization/ dearomatization Acc. Chem. Res. 481979

20. Königs C D F, Klare H F and Oestreich M 2013 Catalytic 1,4-selective hydrosilylation of pyridines and benzannulated congeners Angew. Chem. Int. Ed. 52 10076

21. Liu J, Chen J-Y, Jia M, Ming B, Jia J, Liao R-Z, Tung C-H and Wang W 2019 Ni-O Cooperation versus nickel(II) hydride in catalytic hydroboration of N-heteroarenes ACS Catal. 93849

22. Zhang F, Song H, Zhuang X, Tung C-H and Wang W 2017 Iron-catalyzed 1,2-selective hydroboration of N-heteroarenes J. Am. Chem. Soc. 13917775

23. (a) Stahl $\mathrm{T}$, Muther $\mathrm{K}$, Ohki $\mathrm{Y}$, Tatsumi $\mathrm{K}$ and Oestreich M 2013 Catalytic generation of borenium ions by cooperative $\mathrm{B}-\mathrm{H}$ bond activation: The elusive direct electrophilic borylation of nitrogen heterocycles with pinacolborane J. Am. Chem. Soc. 135 10978; (b) Omann L, Konigs C D F, Klare H F T and Oestreich M 2017 Cooperative catalysis at metal-sulfur bonds Acc. Chem. Res. 501258

24. Lortie J L, Dudding T, Gabidullin B M and Nikonov G I 2017 Zinc-catalyzed hydrosilylation and hydroboration of N-heterocycles ACS Catal. 78454

25. Ji P, Feng X, Veroneau S S, Song Y and Lin W 2017 Trivalent zirconium and hafnium metal-organic frameworks for catalytic 1,4-dearomative additions of pyridines and quinolines J. Am. Chem. Soc. 13915600
26. Feng X, Song Y, Chen J S, Li Z, Chen E Y, Kaufmann M, Wang C and Lin W 2019 Cobalt-bridged secondary building units in a titanium metal-organic framework catalyze cascade reduction of N-heteroarenes Chem. Sci. 102193

27. Fan X, Zheng J, Li Z H and Wang H 2015 Organoborane catalyzed regioselective 1,4-hydroboration of pyridines J. Am. Chem. Soc. 1374916

28. Keyzer E N, Kang S S, Hanf S and Wright D S 2017 Regioselective 1,4-hydroboration of pyridines catalyzed by an acid-initiated boronium cation Chem. Commun. 539434

29. Rao B, Chong C C and Kinjo R 2018 Metal-Free Regio- and Chemoselective hydroboration of pyridines catalyzed by 1,3,2-diazaphosphenium triflate J. Am. Chem. Soc. 140652

30. McGough J S, Cid J and Ingleson M J 2017 Catalytic electrophilic $\mathrm{C}-\mathrm{H}$ borylation using NHC- boranes and iodine forms $\mathrm{C} 2-$, not $\mathrm{C} 3-$, borylated indoles Chem. Eur. J. 238180

31. (a) Wang W-B, Lu S-M, Yang P-Y, Han X-W and Zhou Y-G 2003 Highly enantioselective iridium-catalyzed hydrogenation of heteroaromatic compounds, quinolines J. Am. Chem. Soc. 125 10536; (b) Chen F, Surkus A-E, He L, Pohl M-M, Radnik J, Topf C, Junge $\mathrm{K}$ and Beller M 2015 Selective catalytic hydrogenation of heteroarenes with $\mathrm{N}$-graphene-modified cobalt nanoparticles $\left(\mathrm{Co}_{3} \mathrm{O}_{4}-\mathrm{Co} / \mathrm{NGr} @ \alpha-\mathrm{Al}_{2} \mathrm{O}_{3}\right) \quad J . \quad A m$. Chem. Soc. 3711718

32. Yang C-H, Chen X, Li H, Wei W, Yang Z and Chang J 2018 Iodine catalyzed reduction of quinolines under mild reaction conditions Chem. Commun. 548622

33. Intemann J, Lutz M and Harder S 2014 Multinuclear magnesium hydride clusters: selective reduction and catalytic hydroboration of pyridines Organometallics 335722

34. Lemmerz L E, Spaniol T P and Okuda J 2018 1,4Dihydropyridyl complexes of magnesium: synthesis by pyridine insertion into the magnesium-silicon bond of triphenylsilyls and catalytic pyridine hydrofunctionalization Dalton Trans. 4712553

35. Arrowsmith M, Hill M S, Hadlington T, Kociok-Köhn $\mathrm{G}$ and Weetman C 2011 Magnesium-catalyzed hydroboration of pyridines Organometallics 305556

36. Rauch M, Ruccolo S and Parkin G 2017 Synthesis, structure, and reactivity of a terminal magnesium hydride compound with a carbatrane motif, [Tism $\left.{ }^{\text {PriBenz}}\right] \mathrm{MgH}$ : A multifunctional catalyst for hydrosilylation and hydroboration J. Am. Chem. Soc. 13913264

37. Jeong E, Heo J, Park S and Chang S 2019 Alkoxidepromoted selective hydroboration of $\mathrm{N}$-heteroarenes: Pivotal roles of in situ generated $\mathrm{BH}_{3}$ in the dearomatization process Chem. Eur. J. 251

38. Liu T, He J and Zhang Y 2019 Regioselective 1, 2-hydroboration of N-heteroarenes by potassium-based catalyst Org. Chem. Front. 62749 